Régler les carrières enseignantes : une histoire administrative et syndicale des conseils et commissions (XVII $-\mathrm{XX}^{\mathrm{e}}$ siècles)

\title{
Morphologie et sociologie des lycées et collèges (1930-1938)
}

The morphology and sociology of French secondary schools (1930-1938)

\section{Antoine Prost}

\section{OpenEdition}

\section{Journals}

Édition électronique

URL : https://journals.openedition.org/histoire-education/3228

DOI : 10.4000/histoire-education.3228

ISSN : 2102-5452

Éditeur

ENS Éditions

Édition imprimée

Date de publication : 30 décembre 2016

Pagination : 53-110

ISSN : 0221-6280

Référence électronique

Antoine Prost, « Morphologie et sociologie des lycées et collèges (1930-1938) », Histoire de l'éducation

[En ligne], 146 | 2016, mis en ligne le 30 décembre 2019, consulté le 20 mai 2021. URL : http://

journals.openedition.org/histoire-education/3228 ; DOI : https://doi.org/10.4000/histoire-education 3228

\section{(c) Tous droits réservés}




\title{
Morphologie et sociologie des lycées et collèges (1930-1938)
}

\author{
Antoine Prost
}

Nous connaissons assez mal les élèves qui fréquentaient l'enseignement secondaire entre les deux guerres. Nous ne savons rien sur les collèges privés, qui accueillaient pourtant à peine moins d'élèves que les établissements publics, et pour lesquels, si des sources existent peut-être encore, leur recherche s'apparenterait à celle d'une aiguille dans une meule de foin. Pour les lycées et collèges publics déjà, les archives susceptibles de nous renseigner sont rares, nous y reviendrons. Nous ne disposons même pas d'une statistique rétrospective un peu détaillée ou de bilans analogues à ceux publiés pour les années 1842, $1865,1876,1887$ et 1898 . Peut-on combler cette lacune?

\section{1919 à 1939 : vue d'ensemble}

Un premier regard d'ensemble sur l'évolution des établissements dans l'ensemble de l'entre-deux-guerres, apporte des confirmations et des surprises (graphique 1). Si l'on met en regard de l'effectif annuel des établissements secondaires publics, masculins et féminins, la population scolarisable définie comme celle née 11 à 15 ans plus tôt ${ }^{1}$, on constate que l'enseignement secondaire a relativement bien résisté à la crise de recrutement provoquée par

1 Nous reportons en annexe les tableaux dont sont tirés les graphiques de cet article, ainsi que les indications relatives à leurs sources et à leur mode d'exploitation. La population scolarisable ainsi définie ne tient pas compte de la mortalité depuis la naissance. 


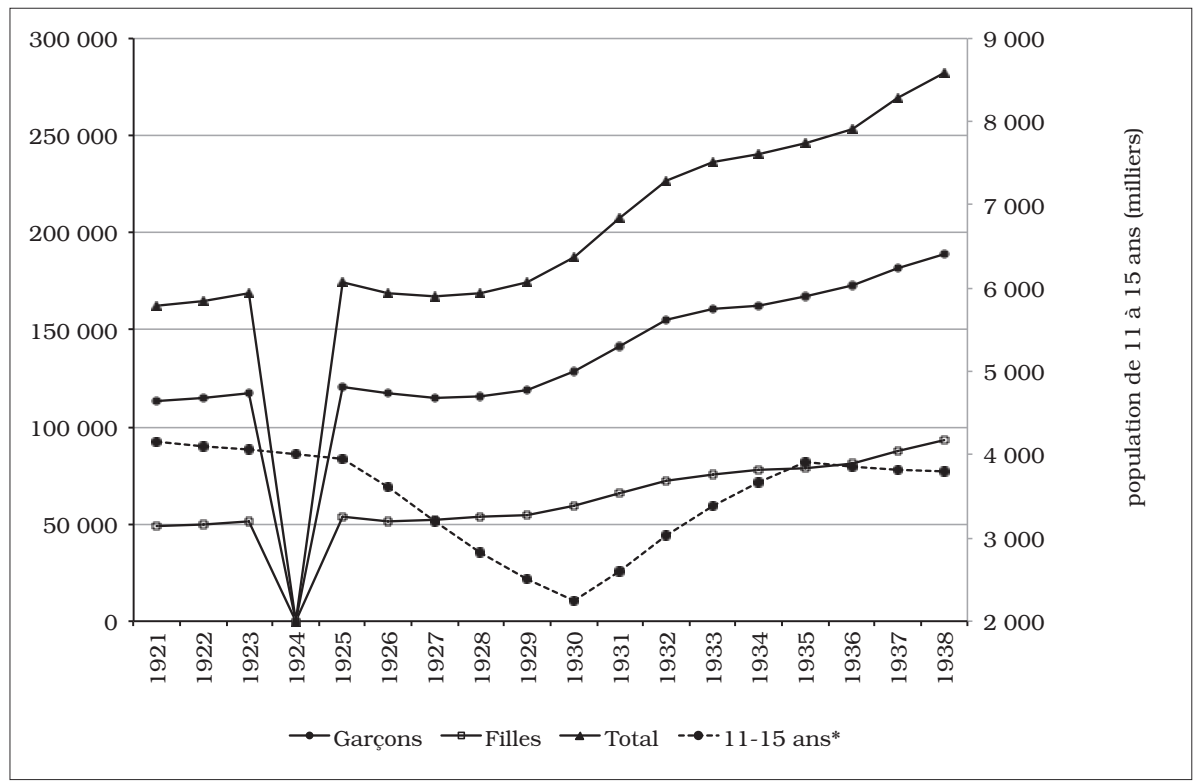

Graphique 1 : effectifs des établissements secondaires 1921-1938

Source : annexes, tableau I.

l'effondrement de la natalité pendant la Grande Guerre. Alors que les effectifs scolarisables étaient divisés par deux, l'effectif des lycées et collèges a peu diminué, comme l'avaient déjà montré Jean-Pierre Briand, Jean-Michel Chapoulie et Henri Peretz ${ }^{2}$. Cette résistance est réelle; elle ne doit rien ou très peu à des élèves "fantômes", imaginés par les chefs d'établissement pour améliorer leurs statistiques. Elle s'explique par l'allongement des scolarités et surtout par un effort de recrutement qui a entraîné une élévation des taux de scolarisation secondaire en sixième et s'est répercuté sur les classes suivantes. On passe d'un taux de 4,2\% de filles et de garçons admis en sixième en 1921-1922, à $5,1 \%$ en 1926-1927, et 7,4\% en 1930. Puis ce taux décline avec l'arrivée des élèves nés après la Grande Guerre, pour se situer à 5,6\% en 1934-1935 et remonter au-dessus de $6,5 \%$ en 1937 et $1938^{3}$.

2 Jean-Pierre Briand, Jean-Michel Chapoulie, Henri Peretz, "Les conditions institutionnelles de la scolarisation des garçons de 1920 à 1940", Revue d'histoire moderne et contemporaine, 1979, n²3, p.391-421; Jean-Michel Chapoulie, L'École d'État conquiert la France, Deux siècles de politique scolaire, Rennes, Presses universitaires de Rennes, 2010, chapitre VII, p. 171-200.

3 Jean-Michel Chapoulie, op. cit., p. 192. 
Cette augmentation du taux de scolarisation s'explique en partie par une moindre sélection. Quand le recul des effectifs menace le maintien des classes, on accepte des élèves plus faibles : la défense de l'emploi passe avant celle du niveau. Mais elle n'est plus de mise quand arrivent les générations d'aprèsguerre, et l'on institue en 1932 un examen d'entrée en sixième. Cependant les nouvelles pratiques de scolarisation se maintiennent et le taux de scolarisation en sixième reste compris entre 5,6 et 7,5\%, un niveau supérieur de moitié à ce qu'il était avant la crise de recrutement. Les effectifs plus importants des sixièmes gonflent donc l'année suivante ceux de cinquième et, d'année en année, les classes se remplissent, ce qui entraîne une croissance importante des effectifs entre la crise et la guerre. De 1929 à 1938, les effectifs totaux du secondaire public ont augmenté de $62,2 \%$, avec une croissance plus rapide pour l'enseignement féminin (70,3 \%) que pour l'enseignement masculin (58,4\%). La gratuité instituée en 1930 n'est probablement pour rien dans cette croissance, comme l'avait vu J.-M. Chapoulie, car le secondaire privé, qui reste payant, connaît lui aussi une augmentation, difficile à chiffrer, mais incontestable ${ }^{4}$.

Si l'élévation du taux de scolarité secondaire est la cause majeure, et de la résistance des établissements à la crise de recrutement, et de leur croissance ultérieure, cette explication reste globale. L'enseignement secondaire est un ensemble composite, qui associe des classes élémentaires et des classes proprement secondaires. C'est particulièrement sensible dans les collèges communaux : leur petite taille les rend vulnérables et ils n'hésitent pas à ouvrir des classes de type primaire supérieur ou professionnel pour pallier la crise démographique. Un effectif global presque stable peut s'accompagner d'importantes variations de l'effectif des composantes. Est-ce le cas?

Le graphique 2 présente l'évolution de l'effectif total de ces diverses composantes dans les divers types d'établissements, et le graphique 3 leur évolution en pourcentages. Ils mettent en évidence une forte différence entre les lycées,

4 La série statistique de l'INSEE donnée dans le tableau I des annexes est trop fragile pour que nous en tirions argument (incertitudes sur la continuité du périmètre et le mode de collecte des données). Pour l'enseignement privé des garçons, l'enquête Ribot donne en 1898 un chiffre fiable : 99178 élèves, y compris les petits séminaires et l'enseignement privé laïque. Pour les mêmes 87 départements, la série de l'INSEE donne 159490 garçons dans le secondaire privé en 1942-1943 et un peu moins l'année suivante. La distinction faite entre filles et garçons suggérant une statistique mieux élaborée, on peut accorder quelque crédit à ce chiffre au demeurant compatible avec ceux, moins incertains encore, des années 1950. Il y a donc eu une croissance du secondaire privé entre 1898 et 1942, et il est peu probable qu'elle se soit produite dans les années qui ont suivi l'interdiction aux congrégations d'enseigner et la séparation des Églises et de l'État. 

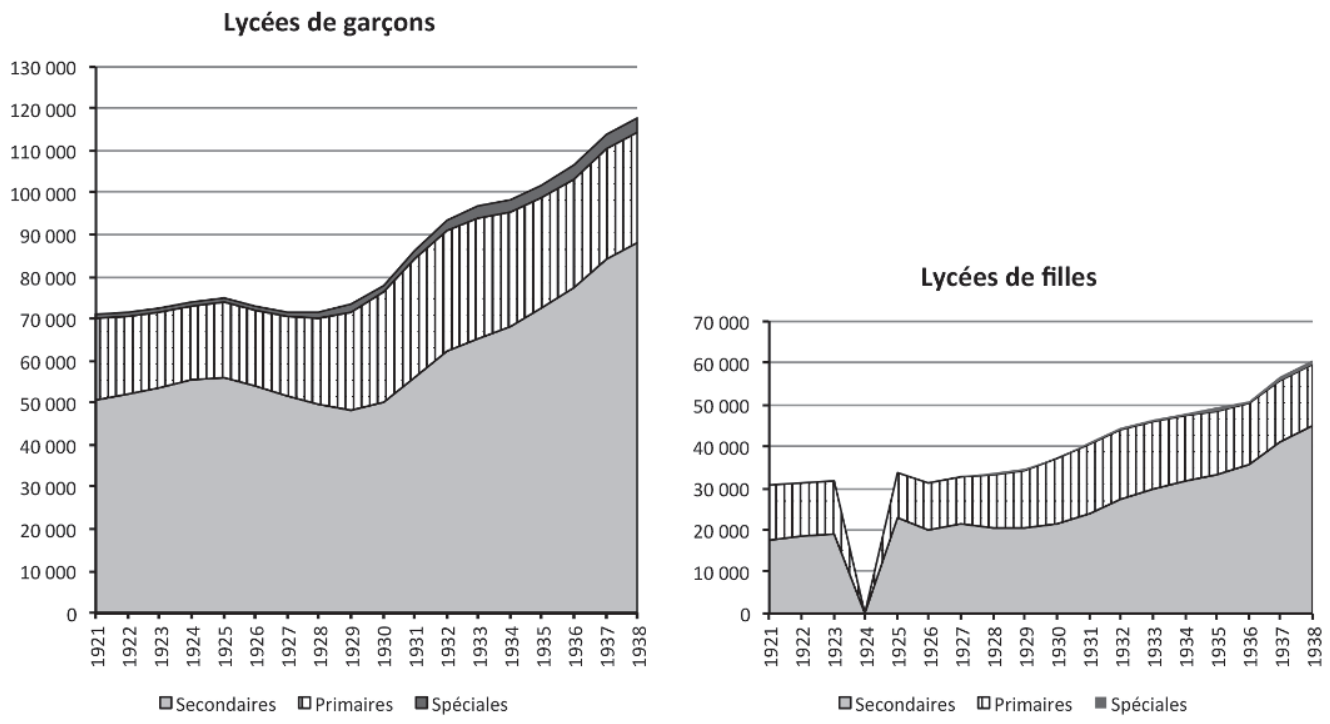

\section{Collèges de Garçons}

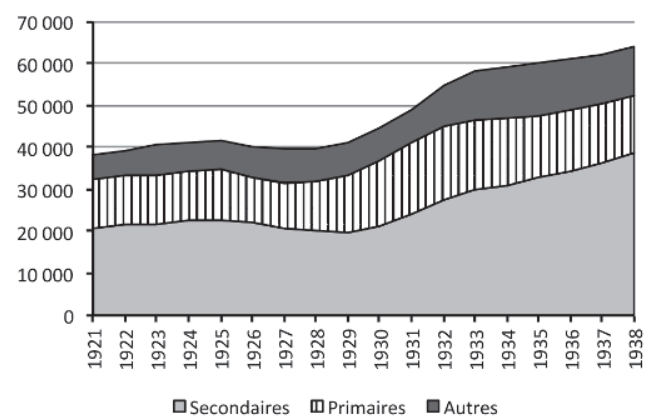

\section{Collèges et cours secondaires de filles}

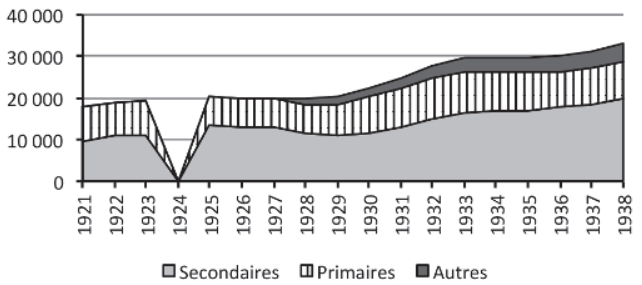

Graphique 2 : composantes de la population des établissements secondaires 
qu'ils soient de garçons ou de filles, et les collèges communaux ${ }^{5}$. Pendant la crise démographique, les lycées compensent une baisse d'effectifs secondaires appréciable, par une croissance de leurs classes élémentaires que repeuplent les générations d'après-guerre. Les lycées de garçons perdent entre 1925 et 1929 $14 \%$ de leurs effectifs secondaires, reculant de 56065 à 48259 élèves, et ceux de filles à peine moins (10,7\%), passant entre les mêmes dates de 22685 à 20252 élèves ${ }^{6}$. On mesure ici l'importance des petites classes : de 1929 à 1931, elles représentent plus du tiers des élèves des lycées de garçons et elles ne descendent en dessous du quart qu'en fin de période, à partir de 1936. Dans les lycées de filles elle est plus grande encore : plus de 40\% en 1929-1931, et moins du quart en 1938 seulement. Dans ces conditions, la réalisation de l'école unique eût été dramatique pour ces établissements. Fondre dans les écoles primaires ces classes élémentaires, restées payantes après l'adoption en 1930 de la gratuité pour les classes secondaires, aurait gravement déséquilibré le budget des lycées : une difficulté rédhibitoire en temps de pénurie budgétaire.

La situation des collèges est plus précaire encore. Dans les collèges de garçons les classes secondaires représentent à peine plus de la moitié de l'effectif, et même un peu moins de 1929 à 1931; puis elles remontent et atteignent $60 \%$ en 1938 seulement. Les classes secondaires pèsent plus lourd dans les collèges de filles, représentant en 1925-1927 près des deux-tiers de leurs élèves; ensuite, la crise démographique se fait durement sentir et ces classes reculent avant de connaître une croissance qui les conduit au même niveau, $60 \%$, que celles des collèges de garçons. La particularité des établissements féminins tient aux petites classes. Dans les collèges de garçons, celles-ci ne dépassent le tiers de l'effectif qu'au plus fort de la crise démographique, de 1929 à 1931, car ces établissements ont très tôt misé sur des classes primaires supérieures ou professionnelles pour augmenter leur effectif total ${ }^{7}$ : en 1927, elles représentent $20 \%$ de leurs effectifs. La crise démographique se fait alors sentir de 1929 à 1932, puis ils remontent jusqu'en 1935, où la croissance des scolarités secondaires amène leur repli. Pour les collèges de filles, la statistique ne donne aucun effectif de sections primaires supérieures ou professionnelles

5 Pour les filles, nous avons joint les cours secondaires aux collèges communaux. Leurs effectifs, très faibles, figurent en annexe, tableau IIe.

6 Annexes, tableaux II.

7 Voir le tableau IIb des annexes, qui donne l'effectif des classes d'EPS, nettement majoritaires, et ceux des sections professionnelles ou d'EPCI. 
Lycées de garçons
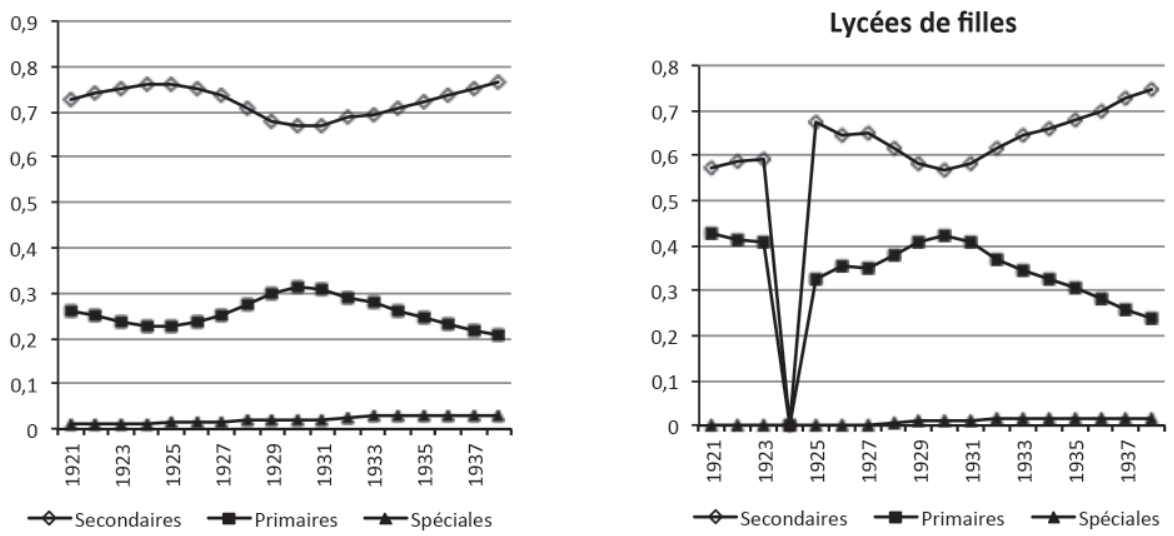

Collèges de garçons

\section{Collèges et cours secondaires de} filles
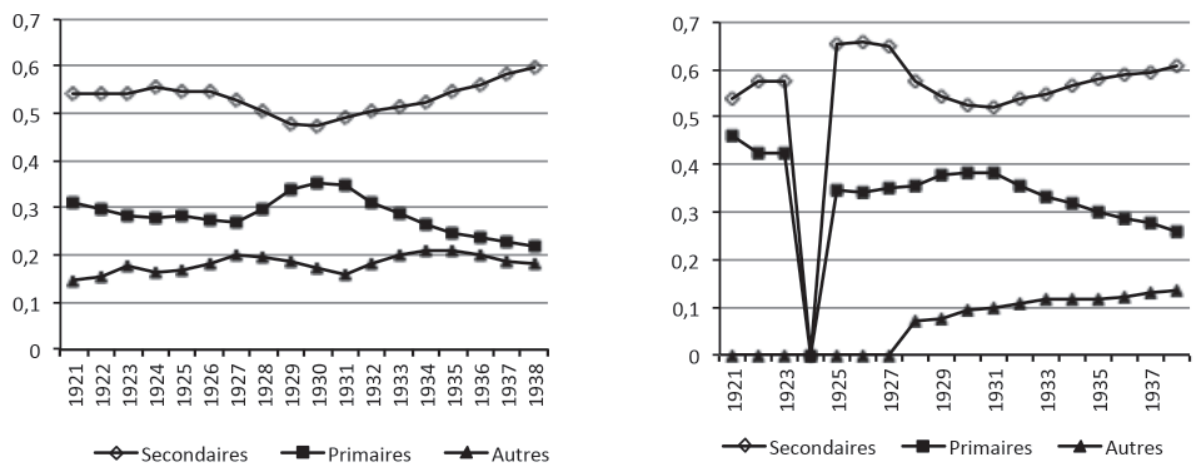

Graphique 3 : importance relative des diverses composantes de la population des établissements secondaires 
avant 1928 : ces collèges ont rarement ouvert de telles classes, quitte parfois à scolariser ensemble dans des sections composites des élèves dont les cursus scolaires et professionnels étaient très différents. L'alignement de l'enseignement secondaire des filles sur celui des garçons, qui commence en sixième en 1924, les aurait obligés à secondariser leurs classes générales, et donc à ouvrir des classes spéciales pour les élèves ne se destinant pas au baccalauréat. En tout cas, ces filières spéciales se développent pendant la crise et au-delà, si bien qu'en fin de période, elles représentent un appoint non négligeable, de 15\% environ.

Il vaudrait donc mieux parler d'établissements "principalement secondaires" que d'établissements "secondaires". Les lycées sont secondaires aux troisquarts en fin de période, après une croissance commencée en 1921, plus forte pour les filles que pour les garçons. Les collèges ne sont que majoritairement secondaires, et ils assurent des formations post-élémentaires très variées.

\section{L'enquête dans les registres d'inscription}

\section{Présentation de l'enquête}

Dans ce contexte, nous avons entrepris une assez large enquête dans les registres d'inscription ${ }^{8}$, pour tenter d'élucider le recrutement des élèves de ces établissements, et notamment savoir si la croissance des années 1930 avait entraîné une certaine démocratisation. Nous avons exclu de la recherche les établissements parisiens, car ils sont très différents de ceux des départements et mériteraient une étude particulière; leurs professeurs forment d'ailleurs des corps différents, aux traitements plus élevés que ceux des provinciaux. La quête a été longue : rares sont les établissements qui ont déposé leurs archives, rares les registres conservés dans ces archives, et plus rares encore ceux qui peuvent nous éclairer.

Les administrations n'enregistrent en effet que les données qui leur semblent utiles, et les registres consignent donc seulement ce que l'Instruction publique, comme il faut l'appeler jusqu'en 1932, a besoin de savoir sur ses élèves : date et lieu de naissance, nom et prénom, adresse des parents, du correspondant pour les internes, classe et qualité de l'élève : interne, demi-pensionnaire, externe surveillé ou externe libre. Parfois ils signalent les bénéficiaires de bourses et les pupilles de la Nation. Au lycée de filles de Dijon, en 1938, on trouve même un 
cahier d'écolier où sont enregistrées les bénéficiaires de bourses. À Carcassonne, la mention "culte" signale les lycéens qui y sont soumis par leurs parents, sans préciser s'il s'agit du culte catholique ou protestant. L'origine scolaire des élèves fait partie de ces indications facultatives; nous ne l'avons trouvée qu'à Privas et à Argentan : le ministère n'a pas besoin de savoir d'où viennent les élèves; il ne gère pas un système, un ensemble de scolarités concaténées, mais des établissements sans rapport les uns avec les autres.

L'origine sociale des élèves fait partie des données qui n'intéressent pas l'administration. Aucune colonne des registres n'est destinée à consigner la profession des parents. Certains secrétariats zélés ont cependant pris parfois l'initiative de noter celle du père, ou de la mère des élèves, avec leur adresse ${ }^{9}$, mais ils sont minoritaires. En outre, au sein d'un même établissement les pratiques ne sont pas nécessairement constantes : les professions sont mentionnées certaines années et non d'autres. Nous n'avons donc pu utiliser tous les registres conservés. Au total, nous avons constitué, à partir des registres de 23 établissements de garçons ou de filles, une base de données comprenant, avec leurs caractéristiques individuelles, tous les élèves inscrits une année, soit en début de période, autour de 1930, soit en fin de période, en 1937 ou 1938. Ceci nous donne un échantillon de 33 établissements-années et 15384 élèves, qui n'est pas totalement représentatif, mais il était difficile de faire mieux ${ }^{10}$. Bien qu'elle ne soit pas exhaustive, cette base de données semble assez large et assez diversifiée pour autoriser des conclusions.

\section{Premiers aperçus}

Ouvrir un registre d'inscription, c'est entrer à la fois dans la routine d'une institution et la singularité d'un établissement. La norme jacobine qui régit ces registres et assure leur uniformité, sauf rares exceptions, en dit beaucoup sur les principes du secondaire tout en laissant transparaitre des originalités inattendues.

Premier constat : l'ordre du registre. Comme la numérotation des classes, il est descendant. Cela nous semble normal, mais on devrait s'en étonner : il serait plus logique de suivre l'itinéraire des élèves. Que dirait-on si l'on appelait premier

9 Il semble que le Front populaire ait commencé à faire bouger les choses, car on voit apparaitre les professions à Arbois en 1938 sur un cahier d'écolier, à Château-Thierry en 1937 sur des registres qui ne les mentionnaient pas jusqu'alors, et de même à Villefranche-sur-Saône en 1941. Comme c'est le seul établissement du Rhône où les professions soient disponibles, nous avons retenu ce registre malgré sa date tardive.

10 La lassitude du chercheur solitaire nous a fait renoncer à examiner 33 départements. 
étage le dernier où s'arrête l'ascenseur? L'enseignement primaire supérieur numérotait ses trois années dans l'ordre où ses élèves les parcouraient, après l'année préparatoire. Dans le secondaire, c'est l'inverse : au terme du parcours figurent les classes préparatoires aux grandes écoles (CPGE), et ce sont elles qu'on trouve en tête des registres, quand elles existent. Au lycée de filles de Bordeaux, par exemple, une classe de préparation à l'ENS de Sèvres-sciences, suivie par une classe de Sèvres-lettres et qui nous réservent une surprise : les 17 élèves de la première sont toutes boursières et 7 sur les 11 de la seconde. L'administration utilisait parfois les bourses pour créer un vivier de futures professeures. Quand il n’y a pas de classe préparatoire, le registre commence par les mathématiques élémentaires, puis la philosophie, et l'on descend ensuite jusqu'au jardin d'enfants, en suivant l'ordre alphabétique des sections : pas question de placer une section B avant une section A! Les classes primaires supérieures, quand elles existent, ferment le ban. Cet ordre définit une institution construite par le haut et il signe la hiérarchie des prestiges scolaires.

En second lieu, les établissements sont loin d'être tous semblables. Ils se différencient d'abord par leur taille. Pour ne considérer que les années 19371938, quel écart entre le collège d'Arbois où Louis Pasteur fit autrefois ses études, avec 88 élèves et le lycée de Saint-Étienne qui en compte 1 134! Mais, dans l'ensemble, ce ne sont pas de gros établissements, même à la veille de la guerre. Si les classes de sixième et cinquième comprennent rarement moins d'une vingtaine d'élèves, les classes terminales sont peu peuplées, même en fin de période, comme le montrent quelques exemples :

\begin{tabular}{l|c|c|c}
\hline Établissement & Date & Maths-Élem. & Philo \\
\hline LG Albi & 1929 & 9 & 14 \\
\hline \multirow{2}{*}{ LG Rochefort } & 1930 & 10 & 24 \\
\cline { 2 - 4 } & 1938 & 21 & 11 \\
\cline { 2 - 4 } & 1930 & 13 & 22 \\
\hline LG Valence & 1938 & 32 & 9 \\
\hline CG Privas & 1938 & 10 & 16 \\
\hline CG Château-Thierry & 1930 & 2 & 20 \\
\hline
\end{tabular}

Tableau 1 : effectifs des classes terminales de quelques établissements de garçons 
À dépouiller ces registres ligne à ligne, on découvre enfin un lien avec les contextes locaux que l'enquête sociologique risque de masquer sous des catégories trop générales. On s'attend à trouver partout les classes supérieures de la société surreprésentées, mais ce ne sont pas les mêmes. Le lycée de Rochefort, par exemple, est peuplé de fils d'officiers de marine : mécaniciens, aviateurs, médecins, intendants. À Saint-Étienne, les ingénieurs de tout poil sont particulièrement bien représentés. À Carcassonne, voici en grand nombre des fils de propriétaires, probablement des viticulteurs aux domaines grands comme sans doute petits. La présence de classes primaires supérieures, parfois une EPS annexée, introduit d'autres différences, qui ne se réduisent pas nécessairement avec la croissance des effectifs dans les années 1930. Au collège de garçons de Soissons, par exemple, qui passe de 252 élèves en 1930 à 402 en 1938, les élèves de primaire supérieur croissent plus rapidement encore, de 60 à 139. Au lycée de Rochefort, ils passent de 127 à 231; comme l'effectif total n'a augmenté que de 105 élèves, ce sont eux qui assurent la croissance de l'établissement. À Gap, ville de montagne aux hivers rudes, on voit arriver comme internes le $1^{\text {er }}$ décembre 46 élèves, tous fils de cultivateurs, qui viennent pour une école d'agriculture d'hiver et qui repartiront à Pâques. Chaque établissement a sa propre personnalité. Notre échantillon permet d'analyser cette diversité parce qu'il entre dans le détail des populations d'élèves et que sa taille le rend globalement représentatif. Il nous permet une sorte de radioscopie des lycées et collèges.

\section{Morphologie des établissements}

\section{La démographie, l'équilibre des cycles et les profils pédagogiques}

L'enseignement secondaire dans son ensemble, on l'a vu, a réagi à la crise démographique en augmentant ses effectifs élémentaires et en s'adjoignant des classes primaires supérieures. L'enquête permet d'affiner cette analyse, puisqu'elle donne l'effectif de chacune des classes des établissements concernés au début et à la fin des années 1930 (voir le graphique 4). Le premier échantillon correspond à la période la plus difficile pour le secondaire : la natalité ayant touché son point bas en 1916, et étant restée très faible les deux années suivantes, le recrutement des classes de sixième a été difficile en 1926. En 1930, ces élèves sont normalement en troisième, et le creux démographique affecte également les classes de quatrième et cinquième. 
À la fin de la période, en revanche, les classes creuses ont quitté les lycées et l'on peut considérer le recrutement comme "normal". Le profil que dessine l'effectif des classes successives se caractérise alors par la prépondérance des classes secondaires, et notamment de celles du premier cycle, avec un léger clocher en sixième. Les classes de second cycle sont à peine moins fournies, avec un léger clocher en première, dû aux redoublements de la première partie du baccalauréat. L'effectif des classes élémentaires a tendance à augmenter de la douzième à la septième, beaucoup de familles ne scolarisant pas leurs enfants avant 6,7 ou 8 ans $^{11}$. Mais surtout, ces classes sont beaucoup moins peuplées que celles du premier cycle. À Saint-Étienne, par exemple, l'effectif de la septième est inférieur de moitié à celui des sixièmes, et c'est moins encore dans la plupart des établissements de l'enquête, puisqu'en moyenne l'effectif des septièmes représente $35 \%$ de celui des sixièmes ${ }^{12}$.

Le profil des établissements féminins en 1937-1938 est un peu différent. Les petites classes sont ici aussi moins peuplées que les classes proprement secondaires, mais l'écart est moindre que dans les établissements masculins : l'effectif des septièmes représente $45 \%$ de celui des sixièmes. Ensuite apparaît une différence sensible; un décrochage se manifeste après la cinquième et se poursuit : on compte en seconde moitié moins d'élèves qu'en sixième. Le clocher de la première se retrouve, mais les élèves de terminale sont moins nombreuses que celles de la seconde, notamment dans les deux collèges de l'échantillon ${ }^{13}$. Survivance de l'ancien diplôme secondaire féminin, que ces établissements préparaient encore une dizaine d'années plus tôt? Toujours est-il qu'une scolarisation longue, sanctionnée par le baccalauréat, ne semble pas répondre à la demande de toutes les familles pour leurs filles, ce que confirme à Saint-Quentin la prospérité des classes primaires supérieures.

Par comparaison à ces profils "normaux", ceux de 1930 manifestent la gravité de la crise de recrutement. Le premier cycle est partout très déprimé, avec notamment, comme prévu, un creux accentué pour la classe de troisième. Le second cycle n'est pas atteint par la crise, et les effectifs de première sont

11 Grandi dans une famille éduquée depuis deux générations, je suis entré en neuvième sachant lire, écrire et compter, et j'ai toujours entendu dire dans ma famille : " 8 ans, huitième". Survivance de la norme antérieure à 1880 où les choses sérieuses, avec le latin, commençaient en huitième?

12 Nous ne prenons pas en compte ici le collège de Villefranche plus tardif (1942), ni le lycée de Sens où l'ouverture de classes d'orientation de Jean Zay gonfle anormalement l'effectif des sixièmes.

135 élèves à Blois et 14 à Saint-Quentin. 
partout, comme en fin de période, supérieurs à la fois à ceux de terminale et de seconde. Le déficit des classes creuses est en partie comblé par l'enseignement élémentaire, qu'on n'est pas étonné de trouver, à Rochefort et à Soissons, plus étoffé qu'à la veille de la guerre. La seule surprise est, dans les grands lycées, l'importance des classes préparatoires, dont l'effectif dépasse à Clermont et à Rennes ceux de toutes les classes, et à Saint-Étienne, ceux des terminales ou de la troisième.

\begin{tabular}{l|c|c|c}
\hline Lycée & CPGE & Troisième & Terminale \\
\hline Clermont-Ferrand 1930 & 97 & 31 & 82 \\
\hline Rennes 1931 & 134 & 30 & 48 \\
\hline Saint-Étienne 1930 & 48 & 36 & 46 \\
\hline Saint-Étienne 1937 & 30 & 120 & 100 \\
\hline
\end{tabular}

Tableau 2 : effectifs des classes de CPGE, troisième et terminales de trois lycées

Comment la crise du recrutement et la croissance des années 1930 ont-elles affecté le fonctionnement des lycées? Deux points appellent l'attention : les classes élémentaires d'une part, les classes primaires supérieures de l'autre.

À la veille de la guerre, on l'a vu, il est matériellement impossible que les petites classes fournissent aux sixièmes le gros de leurs effectifs; on ne peut même pas garantir que $45 \%$ des élèves de sixième viennent de septième dans les établissements de filles et 35\% dans ceux de garçons, car certains élèves de septième ont sans doute quitté l'établissement par suite du déménagement de leurs parents ou pour toute autre raison. À Château-Thierry, où nous pouvons comparer les listes de 1937 et de $1938^{14}$, 5 élèves sur 18 viennent de septième, et 13 d'ailleurs. Comme l'a montré J.-M. Chapoulie, la crise a amené l'enseignement secondaire à élargir son recrutement, et la croissance des années 1930 l'a élargi encore, ouvrant une rupture : contrairement à ce qu'on dit souvent, la sixième ne succède plus à la septième comme la cinquième à la sixième; elle succède de plus en plus à un cours moyen dans une école primaire. Un palier d'orientation possible se met et place.

En 1930, en effet, le rapport entre ces deux classes charnières était différent. Dans les établissements féminins, les septièmes suffisaient presque à remplir les sixièmes : l'écart entre les deux classes était de 6\% seulement. Dans ceux de

14 J'ai pu faire la comparaison parce qu'un professeur du lycée, Tony Legendre, m'a aimablement procuré une copie du registre. Qu'il en soit vivement remercié. 


\section{Lycées et collèges de garçons}
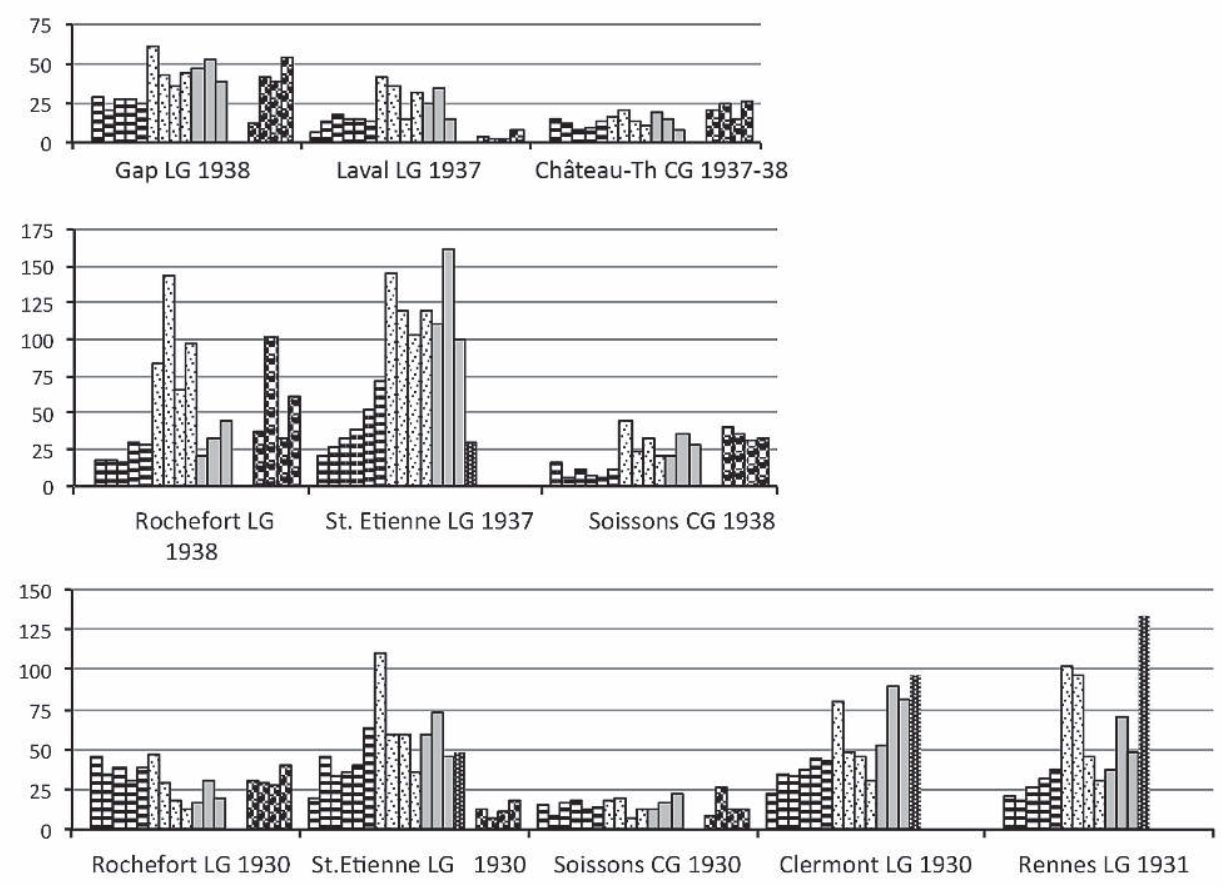

Lycées et collèges de filles
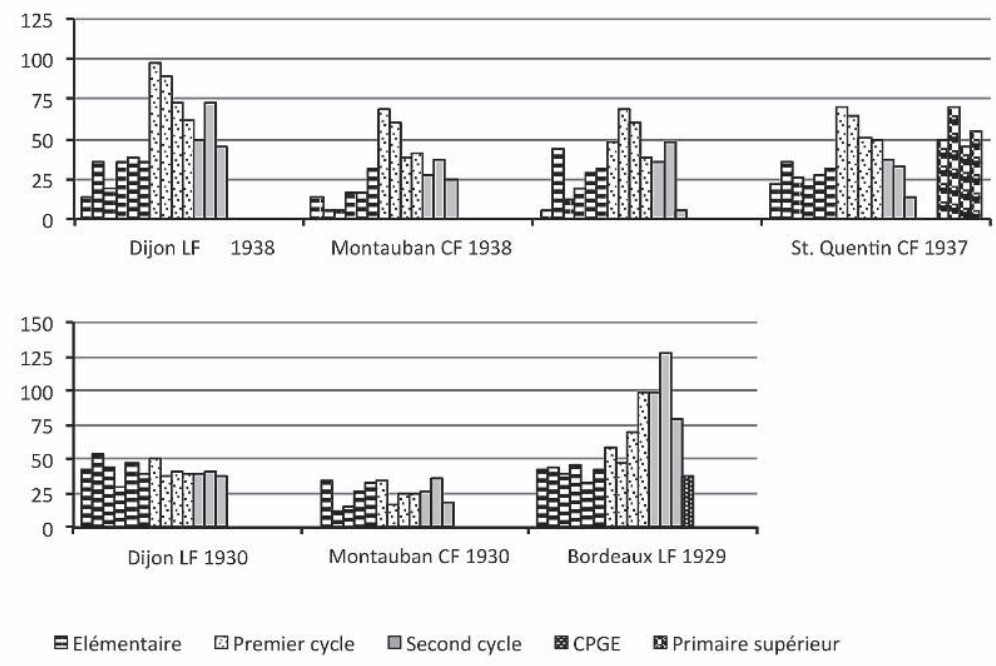

Graphique 4 : profils de quelques lycées et collèges de garçons et de filles à la fin et au début des années 1930 
garçons, l'écart était plus fort, mais nettement inférieur à celui de 1938, puisque les septièmes représentaient $54 \%$ de l'effectif des sixièmes, contre $35 \%$ huit ans plus tard. À Privas, où l'origine scolaire des élèves est mentionnée en 1930, sur 16 élèves de sixième, 6 venaient de la septième, autant d'une école primaire publique, un d'une école privée, et 3 d'ailleurs. Au collège d'Argentan ${ }^{15}$, pour la totalité de la période 1920-1934, sur 264 élèves de sixième, 169 venaient de septième, soit $64 \%$, un taux très supérieur à ceux de la fin des années trente. Mais sur ces 264 élèves, 124 seulement vont au-delà de la cinquième, 75 jusqu'à la troisième, et 46 jusqu'au terme du secondaire. Le profil de ce collège, pour une période antérieure en partie aux années trente il est vrai, s'apparente à ceux du XIX ${ }^{e}$ siècle, avec beaucoup de scolarités secondaires incomplètes et un très fort renouvellement des élèves, notamment dans les petites classes.

La seconde réponse à la crise du recrutement était de développer les classes primaires supérieures. C'est le fait surtout de collèges communaux, où la différence culturelle et sociale entre les deux ordres d'enseignements est moins grande - on voit même à Argentan certains élèves se présenter en septième au certificat d'études primaires puis entrer en apprentissage - ou de lycées de petite taille. Pourtant, celui de Saint-Étienne s'y est essayé en 1930, avec sans doute peu de succès, car ces classes n'existent plus en 1937 : nées de la crise, elles ont disparu avec elle. Mais ailleurs il est arrivé qu'elles prospèrent. En 1938 à Rochefort, un lycée un peu atypique, le profil du primaire supérieur est identique, un cran plus bas, à celui du premier cycle ${ }^{16}$, et les classes primaires supérieures sont plus étoffées que celles du second cycle. À Gap, le primaire supérieur pèse moins, mais, on l'a vu, ce lycée accueille en outre une école d'agriculture d'hiver qui n'est pas représentée sur le graphique. Dans les deux collèges d'Argentan et de Château-Thierry, en revanche, le premier cycle secondaire compte moins d'élèves que l'ensemble primaire supérieur. Notre échantillon comprenant pour cette période 7 lycées de garçons et 4 collèges ${ }^{17}$, il ne faudrait pas accorder à ces remarques un caractère de généralité qu'elles

15 Actuel lycée Mézeray dont je remercie le proviseur de m’avoir donné en 2004 une copie du registre d'inscription. Celui-ci, tenu comme les registres matricules des écoles primaires, inscrit les élèves au fur et à mesure de leur arrivée, et indique la classe où ils entrent, puis la classe où ils se trouvaient lors de leur sortie. Il arrive que certains élèves, entrés en cinquième soient relégués en sixième avant de quitter le collège.

16 Du fait de l'existence d'une classe préparatoire, la première année de primaire supérieur correspond à la cinquième du secondaire, et la troisième année à la troisième.

17 Le collège de Villefranche-sur-Saône en 1942 a été écarté de cette analyse. 
n'ont pas. Elles indiquent cependant qu'à la veille de 1939, les établissements secondaires ne répondent pas partout exclusivement à une demande proprement secondaire.

Mais suffit-il que les élèves de primaire supérieur soient inscrits sur les mêmes registres - en fin de registre il est vrai - pour qu'ils soient de véritables lycéens? Ces classes sont-elles une entité à part dans l'établissement, ou entretiennent-elles des rapports avec les autres classes? Le registre de Château-Thierry invite à répondre par la négative. Les échanges entre classes secondaires et primaires supérieures se limitent à deux élèves, entrés en année préparatoire en 1938, l'un au sortir de la septième, l'autre de la sixième moderne. Aucun élève du primaire supérieur n'est passé dans le secondaire, et aucune des trois années primaires supérieures n'a accueilli de transfuge du secondaire. Les deux filières sont étrangères l'une à l'autre. Le développement d'un primaire supérieur dans le secondaire semble plus qu'un expédient destiné à pallier la crise de recrutement, car il lui arrive de prospérer après elle, mais il n'a manifestement pas suscité de rapprochement entre les deux filières. L'unification de leurs programmes par Jean Zay conduisait, dans ces conditions, à réduire l'originalité pédagogique du primaire supérieur plutôt qu’à rénover le secondaire moderne.

L'hétérogénéité de l'enseignement secondaire des années trente est en tout cas manifeste. Non seulement établissements de filles et de garçons entretiennent des différences sensibles, mais ces différences affectent leur cœur : leur profil pédagogique et leur fonctionnement interne. Elles tiennent à leur taille, mais aussi à l'environnement auquel ils s'adaptent et sans doute à leur histoire. Des monographies détaillées permettraient seules d'esquisser une typologie complexe. L'étude des internats le confirme.

\section{La croissance des effectifs et l'internat}

$\mathrm{Au} \mathrm{XIX}^{\mathrm{e}}$ siècle, la faiblesse de l'urbanisation et les conditions de transport rendaient l'internat indispensable. Au tournant du $\mathrm{XX}^{\mathrm{e}}$ siècle, il jouait encore un rôle important dans la concurrence entre établissements publics et privés ${ }^{18}$. Les lycées comptaient alors $26 \%$ d'internes, et les collèges communaux $31 \%$, contre $60 \%$ pour les établissements privés confessionnels.

18 Antoine Prost, "De l'enquête à la réforme : l'enseignement secondaire des garçons de 1898 à 1902 ", Histoire de l'éducation, $\mathrm{n}^{\circ} 119$, juillet-septembre 2008, p. 29-80. 


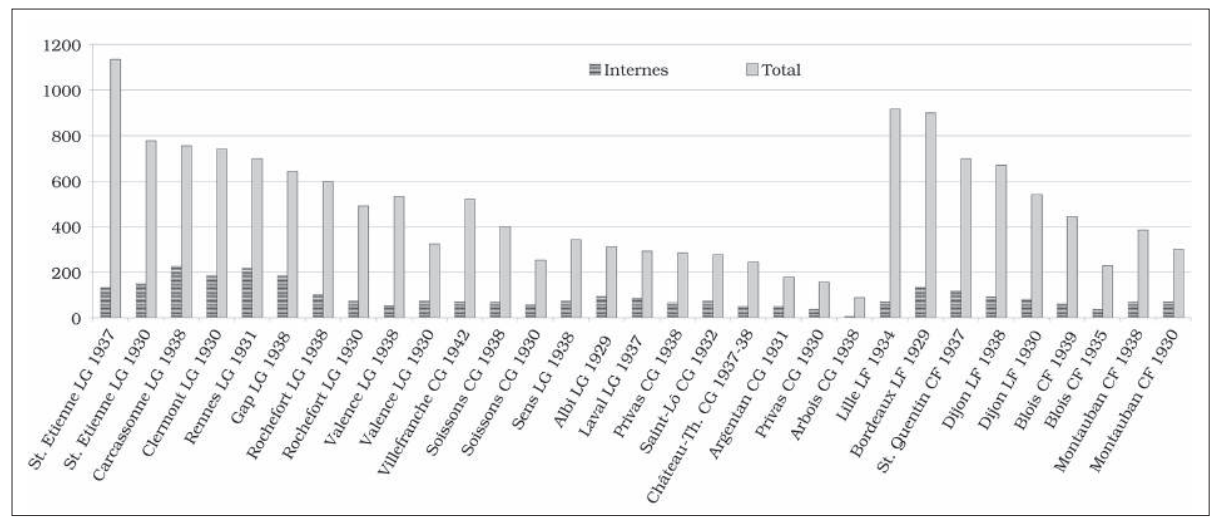

Graphique 5 : effectif total des établissements et effectif d'internes

La Statistique générale de la France agrégeant pensionnaires et demi-pensionnaires, nous ne savons pas précisément quelle était la situation en 1930, mais la proportion d'internes dans l'échantillon s'élevant alors en moyenne à $24 \%$ pour les lycées et $25,5 \%$ pour les collèges de garçons, il semble que le recul de l'internat ait été assez modeste depuis le début du siècle ${ }^{19}$. La comparaison n'a pas grand sens pour les établissements féminins, car la loi de 1880 qui les a créés laissait leurs internats à la charge des villes et ils se sont développés lentement. Traditionnel pour les garçons, l'internat était une innovation pour les filles. Il semble qu'elle ait plutôt réussi : les établissements féminins de l'enquête comptent autour de 15\% d'internes et, surtout, tous disposent d'un internat, même celui de Blois, malgré le statut juridique de cours secondaire qu'il conserve. Les lycées de filles des grandes villes, comme Lille ou Bordeaux, n'ont pas besoin de l'internat pour grossir leur effectif, mais il remplit une fonction sociale, permettant l'accueil de boursières, et il est indispensable pour les classes préparatoires dont l'aire de recrutement déborde de beaucoup l'agglomération. À Bordeaux, 40\% des internes reçoivent une bourse de l'État et sur 37 élèves qui préparent l'ENS de Sèvres, lettres ou sciences, 26 sont internes et 25 boursières. Ces classes ne vivraient pas sans internat et sans bourses.

L'existence d'internats suppose des locaux adaptés, car il est plus difficile de créer un dortoir qu'une salle de classe. Cette moindre flexibilité explique d'abord, comme le montre le graphique 5, que la proportion d'internes varie

19 L'ensemble des pensionnaires et demi-pensionnaires, qui représentait $37 \%$ de la population des lycées en 1900, en regroupe $30 \%$ en 1930. 
sensiblement entre établissements, et que le nombre d'internes n'a guère de rapport avec l'effectif total. Dans huit établissements de garçons seulement ${ }^{20}$, il dépasse le quart de l'effectif. Elle explique ensuite que le doublement des effectifs secondaires entre 1930 et 1938 ne se soit pas accompagné d'une croissance analogue du nombre d'internes. Au lycée de garçons de Valence, il tombe en dessous de $10 \%$ en 1938 alors qu'en 1930 il atteignait $23 \%$. À SaintÉtienne, il a diminué de 152 à 133, soit d'un peu moins de $20 \%$, à 11,7\% du total des élèves. Globalement, la proportion d'internes dans les établissements masculins de l'échantillon baisse de 24,3 à 19,3\% dans les années trente, soit une perte d'un cinquième. La croissance de la scolarisation a fait davantage reculer l'internat dans les dix années qui ont suivi 1930 qu'au cours des trente années qui l'ont précédé.

Mais l'internat a-t-il pour autant changé de fonction? Répondre à cette question passe par l'examen de l'âge et de la classe des internes. Or les deux données ne sont pas aussi solidaires qu'aujourd'hui, car les classes étaient à l'époque moins strictement définies par l'âge. En 2014, les élèves de sixième ont presque tous 11 ans : $12 \%$ seulement ont 12 ans et $2,9 \% 10$ ou moins ${ }^{21}$. Dans les années 1930, ils étaient généralement plus âgés : autour de 40\% avaient 12 ans, un peu moins 11 ans, et il y avait davantage d'élèves plus âgés ou plus jeunes, avec 15 à $20 \%$ d'élèves de 13 ans ou plus, et $10 \%$ de 10 ans ou moins $^{22}$. À leur entrée en première, aujourd'hui, 4,9\% d'élèves ont 15 ans ou moins, $75,9 \% 16$ ans, $16,8 \% 17$ et $2,4 \% 19$ ou plus ${ }^{23}$. Entre les deux guerres, la proportion d'élèves de 16 ans était deux fois moins forte, et elle a diminué du début à la fin des années 1930, pour les garçons comme pour les filles, alors que celle des élèves de 17 ans augmentait, pour représenter $40 \%$ du total, contre un peu plus de $25 \%$ pour ceux de 16 ans. Près d'un élève sur quatre avait 18 ans ou plus, et un sur dix 15 ans ou moins. La gestion des élèves en fonction de leur âge était alors beaucoup moins resserrée qu'aujourd'hui, et l'idée trop généralement reçue selon laquelle les bacheliers étaient plus jeunes autrefois qu'aujourd'hui est une idée fausse.

20 Lycées de garçons de Carcassonne 1938, Clermont-Ferrand 1930, Rennes 1931, Gap 1938, Albi 1929, Laval 1937; collèges de Saint-Lô 1932, Argentan 1931.

21 Ministère de l'Éducation nationale, Repères et références statistiques 2015, p.99.

22 On notera la distribution particulière des garçons en 1930, effet de la crise démographique.

23 Repères et références statistiques 2015, p. 113. 


\begin{tabular}{c|r|r|r|r|r|r|r|r|r|r|r}
\hline \multicolumn{5}{c}{ Classes de 6e } & \multicolumn{5}{c}{ Classes de 1 $^{\text {re }}$} \\
\hline Age & $\begin{array}{r}\text { Filles } \\
\mathbf{1 9 3 0}\end{array}$ & $\begin{array}{r}\text { Filles } \\
\mathbf{1 9 3 8}\end{array}$ & $\begin{array}{c}\text { Garçons } \\
\mathbf{1 9 3 0}\end{array}$ & $\begin{array}{c}\text { Garçons } \\
\mathbf{1 9 3 8}\end{array}$ & $\mathbf{2 0 1 4}$ & Age & $\begin{array}{c}\text { Filles } \\
\mathbf{1 9 3 0}\end{array}$ & $\begin{array}{c}\text { Filles } \\
\mathbf{1 9 3 8}\end{array}$ & $\begin{array}{c}\text { Garçons } \\
\mathbf{1 9 3 0}\end{array}$ & $\begin{array}{c}\text { Garçons } \\
\mathbf{1 9 3 8}\end{array}$ & $\mathbf{2 0 1 4}$ \\
\hline 9 & $1 \%$ & $1 \%$ & $1 \%$ & $0 \%$ & $0 \%$ & 14 & $2 \%$ & $0 \%$ & $2 \%$ & $0 \%$ & $0 \%$ \\
\hline 10 & $13 \%$ & $11 \%$ & $24 \%$ & $11 \%$ & $3 \%$ & 15 & $7 \%$ & $8 \%$ & $7 \%$ & $9 \%$ & $5 \%$ \\
\hline 11 & $28 \%$ & $29 \%$ & $34 \%$ & $25 \%$ & $85 \%$ & 16 & $36 \%$ & $26 \%$ & $33 \%$ & $27 \%$ & $76 \%$ \\
\hline 12 & $39 \%$ & $40 \%$ & $30 \%$ & $43 \%$ & $12 \%$ & 17 & $35 \%$ & $40 \%$ & $36 \%$ & $40 \%$ & $17 \%$ \\
\hline 13 & $16 \%$ & $14 \%$ & $8 \%$ & $16 \%$ & $1 \%$ & 18 & $15 \%$ & $19 \%$ & $18 \%$ & $20 \%$ & $2 \%$ \\
\hline 14 & $2 \%$ & $5 \%$ & $3 \%$ & $4 \%$ & $0 \%$ & 19 & $4 \%$ & $7 \%$ & $5 \%$ & $4 \%$ & $0 \%$ \\
\hline 15 & $1 \%$ & $1 \%$ & $1 \%$ & $0 \%$ & $0 \%$ & 20 & $2 \%$ & $1 \%$ & $1 \%$ & $1 \%$ & $0 \%$ \\
\hline $\mathbf{N}$ & $\mathbf{1 4 8}$ & $\mathbf{3 2 4}$ & $\mathbf{5 3 2}$ & $\mathbf{8 8 1}$ & & $\mathbf{N}$ & $\mathbf{1 9 6}$ & $\mathbf{1 7 2}$ & $\mathbf{3 9 6}$ & $\mathbf{5 9 2}$ & $\mathbf{5 9 2}$ \\
\hline
\end{tabular}

Tableau 3 : élèves de sixième et de première selon l'âge en 2014 et autour de 1930 et 1938

Ces remarques obligent à distinguer, dans l'analyse du statut des élèves de l'entre-deux-guerres, la classe et l'âge. Les graphiques 6 permettent de voir comment ont évolué selon les deux critères les proportions d'internes, d'externes et d'élèves, demi-pensionnaires ou externes surveillés, qui suivent une partie des études auxquelles sont astreints les internes.

D'emblée apparaissent trois changements. D'abord, si l'externat progresse pendant la période et s'il est plus fréquent chez les filles que chez les garçons, tandis que ceux-ci, en vieillissant, sont de plus en plus externes, cette progression s'arrête pour les filles autour de 14 ans. Le contraste est frappant. La courbe d'internes féminines décolle brusquement en sixième et elle se maintient à $20 \%$ pendant le premier cycle (1938), puis elle recule au second. Ceci renforce l'impression que donnaient déjà les scolarités incomplètes : l'important, pour l'enseignement secondaire des jeunes filles, c'est encore une scolarité courte qui ne vise pas le baccalauréat. En revanche, pour les deux sexes, l'entrée en classe préparatoire s'accompagne souvent de l'internat.

L'examen du statut des garçons confirme le rôle décisif de la classe : l'entrée en sixième marque une rupture : les petites classes ont une écrasante majorité d'externes, 69\% en début de période, plus des trois-quarts à la veille de la guerre. Avant ce seuil, les familles préfèrent des formes de prise en charge, demi-pension ou externat surveillé, qui leur laissent leurs enfants le soir. L'internat des enfants n'a pourtant pas disparu, mais il est plus sensible à l'âge qu'à la classe. En 1930, en huitième, on compte $7 \%$ de pensionnaires chez les 

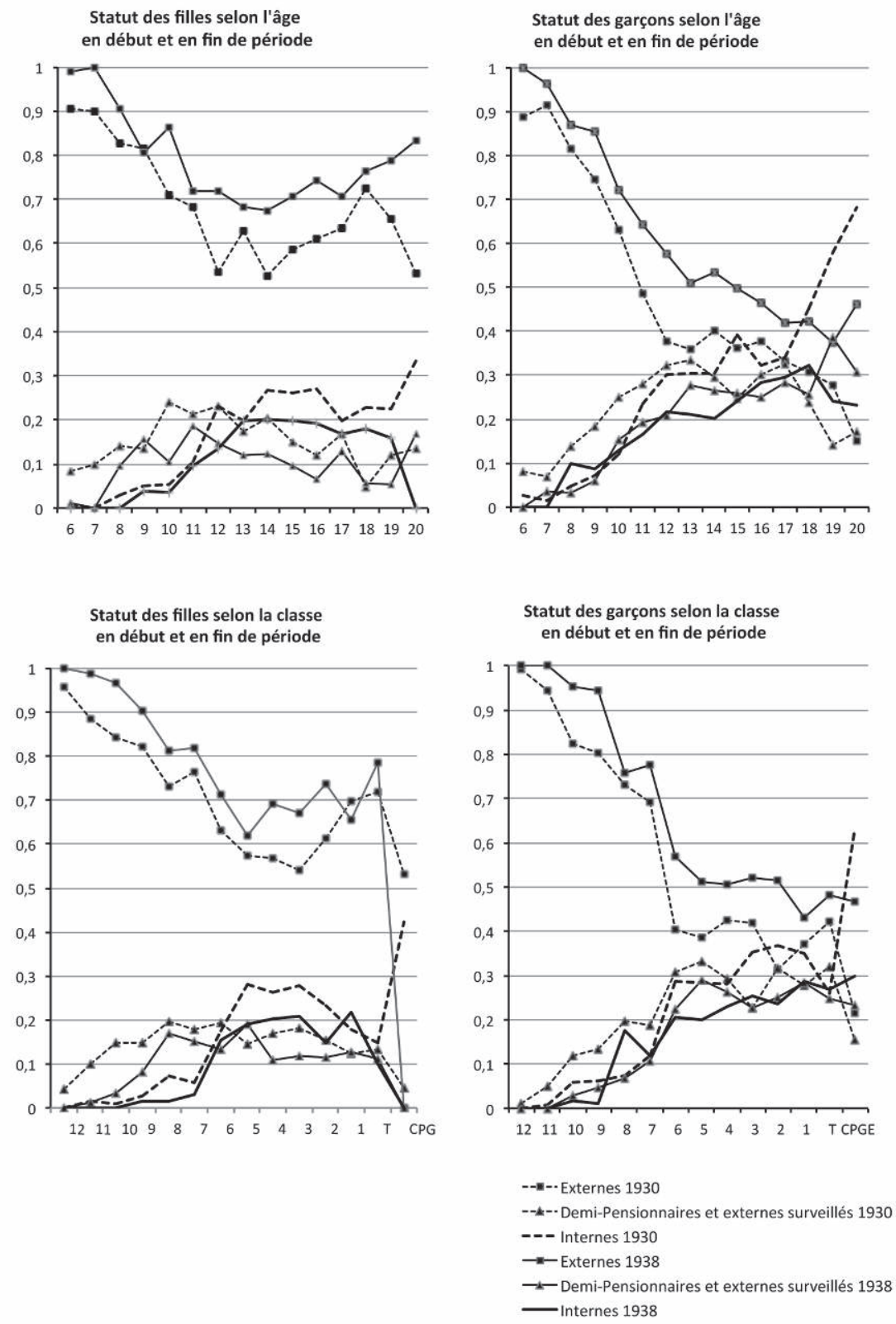

Graphique 6 : statut des filles et des garçons selon l'âge et selon la classe en début et en fin de période 
filles, contre seulement 3\% parmi les élèves de huit ans, et chez les garçons, $7 \%$ contre $5 \%$. Avant huit ans, les internes sont des exceptions, rarissimes à la veille de la guerre. Sur ce point, le XIX ${ }^{e}$ siècle est en train de prendre fin.

Reste que l'enseignement secondaire proprement dit compte encore autour d'un interne sur cinq élèves. Cela laisse prévoir de grosses difficultés pour les années noires qui suivront.

\section{Les aires de recrutement}

L'internat entretient d'évidents rapports avec la distance du domicile familial à l'établissement, mais ce lien est difficile à formaliser. En effet, nos informations sur le domicile des parents sont sommaires : une adresse. Nous ne pouvons entrer dans l'analyse fine des territoires, car la réalité administrative des communes n'a pas grand sens géographique. Nous pourrions considérer que La Madeleine, par exemple, fait partie de Lille, mais en ce cas il faudrait agréger à Lille d'autres communes, et où fixer la limite? Nous n'avons en fait que cinq catégories exploitables : la commune qui accueille l'établissement, le département, les départements limitrophes, le reste de l'Hexagone, et le hors-métropole, étranger et colonies, qui fournissent un trop petit nombre d'élèves pour qu'on les distingue. Catégories d'usage précaire, car pour prendre le département de l'Aisne, l'attraction géographique des établissements de Saint-Quentin n'a guère de points communs avec celle du collège de Château-Thierry. Nous n'avons pourtant d'autre choix que de les utiliser.

Contrairement à ce qu'on aurait pu attendre, le nombre d'internes n'augmente pas quand diminue celui des élèves dont la famille habite la ville même du lycée ou collège. La corrélation entre les pourcentages d'internes et d'habitants de la commune n'est pas statistiquement significative, avec un coefficient de corrélation négatif très faible $: r=-0,44^{24}$. En fait, la définition administrative de la commune n'a pas de réalité géographique, et la proportion d'internes obéit à un trop grand nombre de déterminants pour être vraiment expliquée. On l'a vu, le profil pédagogique joue un rôle : comme les internes se recrutent à partir de la sixième, leur importance est moindre dans l'établissement si les petites classes sont étoffées. L'étroitesse de leurs bassins de recrutement conduit les petits collèges à rechercher des internes pour compenser l'insuffisance de la

24 Le coefficient de corrélation varie de 0 à 1 ou -1. Un coefficient de 0,44 explique, si l'on peut dire, $20 \%$ du phénomène étudié. Le coefficient est négatif si une variable diminue quand l'autre croît. 


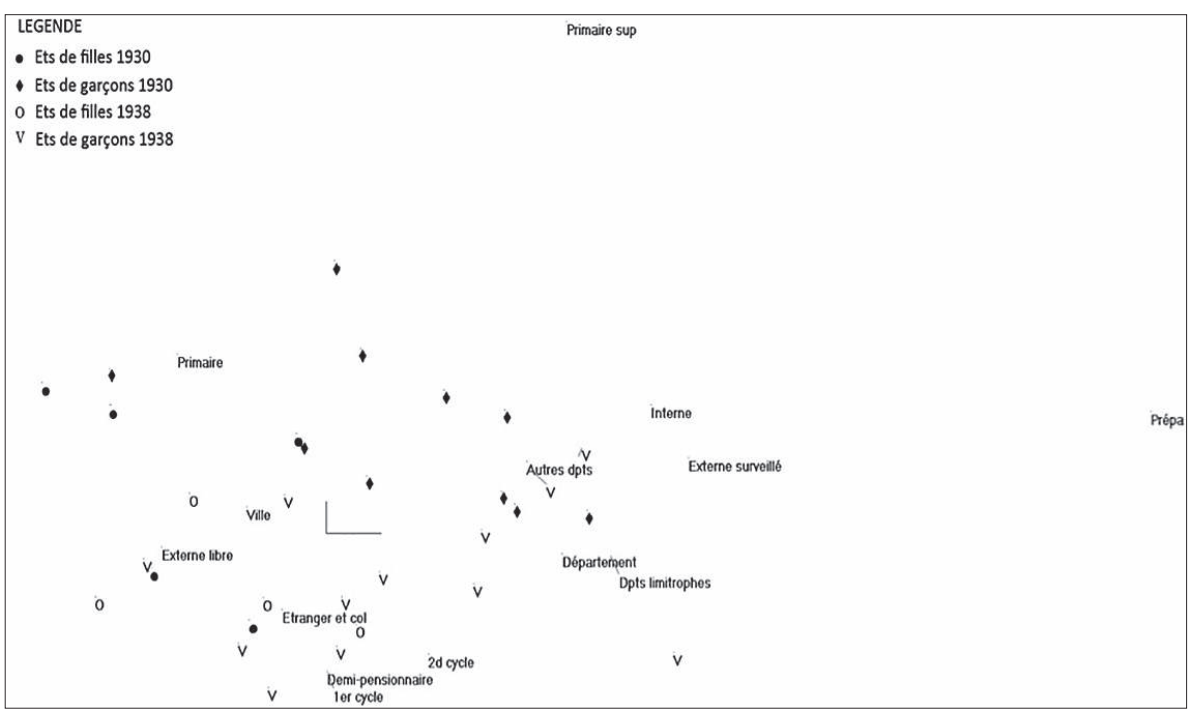

Graphique 7 : établissements de filles et de garçons en début et en fin de période selon leurs caractères morphologiques

clientèle locale, alors que dans les grandes villes les externes suffiraient presque à remplir les classes. Tous ces facteurs sont interdépendants. Leur combinaison permettrait-elle d'établir une typologie?

Pour le tenter, nous avons soumis ces données à une analyse factorielle des correspondances $(\mathrm{AFC})$, pour situer chaque établissement en fonction des trois critères morphologiques : le statut des élèves (interne, etc.), le profil pédagogique de l'établissement (primaire, $1^{\text {er }}$ cycle, etc.) et les domiciles familiaux ${ }^{25}$. Sans être spectaculaires - les deux premiers facteurs de l'AFC extraient respectivement $30 \%$ et $18 \%$ de l'information, soit un peu moins de la moitié - les résultats sont assez intéressants (graphique 7).

Le premier axe est déterminé par le statut des élèves : les établissements d'externes s'opposent à ceux où internes et externes surveillés pèsent davantage. La variable primaire est logiquement du côté des externes, mais sur le second axe qui est déterminé par le niveau d'études, elle s'oppose nettement aux $1^{\text {er }}$

25 J'ai utilisé le logiciel Tri2 de Philippe Cibois, que je remercie chaleureusement pour son aide. En raison de leur caractère très particulier, susceptible de déterminer les axes à eux seuls, les effectifs des classes préparatoires et des classes primaires supérieures ont été traités en variables supplémentaires. 
et $2^{\mathrm{d}}$ cycles. Très chargées en internes, les classes préparatoires sont chassées très loin du centre de gravité, du côté positif du premier axe, et le primaire supérieur du côté positif du second. Le domicile familial n'intervient que pour définir le troisième axe (non représenté), avec un rôle très faible du pourcentage d'élèves de la commune, trop semblable dans les divers établissements pour les différencier, et une opposition entre deux minorités, les élèves venus du département d'une part, et ceux qui viennent des départements voisins ou du reste de la France de l'autre. Cette hiérarchie, qui donne au rapport entre internat et externat le premier rôle dans la diversification des établissements, surprend un peu, mais son lien avec le profil pédagogique qui ordonne le second axe est logique. Le troisième critère semble en revanche indépendant.

Cette configuration factorielle fait apparaître deux différences intéressantes. La première donne à tous les établissements féminins, minoritaires dans notre échantillon comme dans l'ensemble des établissements de l'époque, une place dans la zone négative du premier axe : ils se distinguent des établissements masculins par l'importance des petites classes et le petit nombre d'internes. La seconde différence est chronologique : en fin de période, les établissements sont comme tirés vers le bas, et un peu vers la droite, ce qui traduit avant tout le développement des premier et second cycles. Le constat est très net pour les établissements qui figurent dans l'échantillon à la fois en début et en fin de période : tous reculent fortement sur le second facteur. L'évolution du profil pédagogique, une fois liquidée la crise de recrutement née de la guerre, est très sensible. Signifie-t-elle le début d'une démocratisation?

\section{Sociologie des établissements}

\section{Des établissements bourgeois sensibles au genre}

Que les établissements secondaires recrutent leurs élèves au sein de la bourgeoisie n'est pas pour surprendre, mais l'analyse permet seule d'affiner ce constat établi depuis longtemps. Nous expliquons dans l'annexe 3 la façon dont nous avons construit les catégories utilisées pour y parvenir. Elles diffèrent des taxinomies habituelles sur deux points. D'abord nous distinguons entre les ouvriers qui n'ont pas de compétence professionnelle et ceux dont la qualification rend impossible de savoir s'ils sont salariés ou artisans à leur compte, et que nous appelons "gens de métier". Ensuite, une précédente étude nous ayant montré que les cadres du secteur privé envoyaient plutôt 


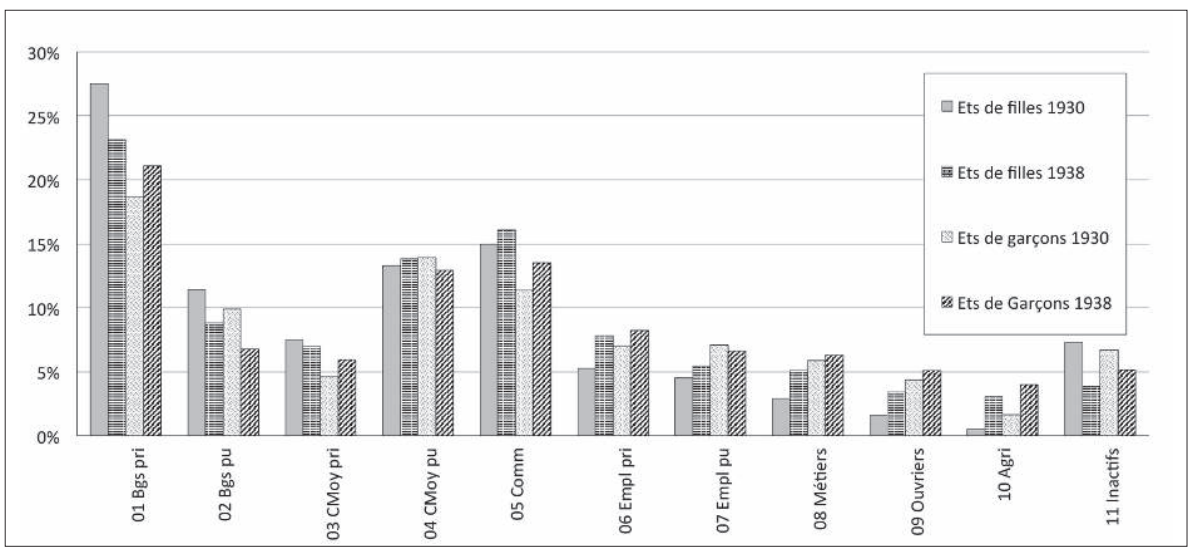

Graphique 8 : milieu social des élèves selon le sexe en début et en fin de période

leurs enfants dans des établissements privés et inversement ${ }^{26}$, nous avons distingué les deux secteurs privé et public pour la bourgeoisie, les cadres moyens et les employés.

Premier constat: les classes moyennes (commerçants inclus) pèsent un peu plus que la bourgeoisie. Si l'on agrège les données, sur l'ensemble de l'échantillon, on obtient $33,3 \%$ d'enfants de commerçants et de classes moyennes publiques ou privées, contre 30,3\% d'enfants de la bourgeoisie. Alors que les deux groupes font jeu égal en début de période, l'écart semble se creuser au cours des années trente, puisqu'en fin de période il est de 33,6\% contre $29 \%$. Serait-ce un indice de démocratisation? Nous reviendrons sur ce sujet en analysant de plus près les établissements pour lesquels nous disposons des deux séries de données.

Cette première conclusion appelle pourtant une réserve : les inactifs sont nombreux. Il ne s'agit pas des rentiers et propriétaires, qui ont été classés dans la bourgeoisie privée, mais de personnes sans profession indiquée. Parmi eux, presque trois-quarts $(63,7 \%)$ de femmes seules, dont beaucoup de veuves de guerre. On manque de repères pour leur assigner une position sociale. Il y a là un facteur d'incertitude propre à la période.

Second constat : les établissements de filles semblent un peu plus bourgeois que ceux de garçons, en début comme en fin de période. L'écart pourrait tenir

26 Antoine Prost, L'enseignement s'est-il démocratisé? Les élèves des lycées et collèges de l'agglomération d'Orléans de 1945 à 1980, Paris, Presses universitaires de France, 1985 et 1992. 


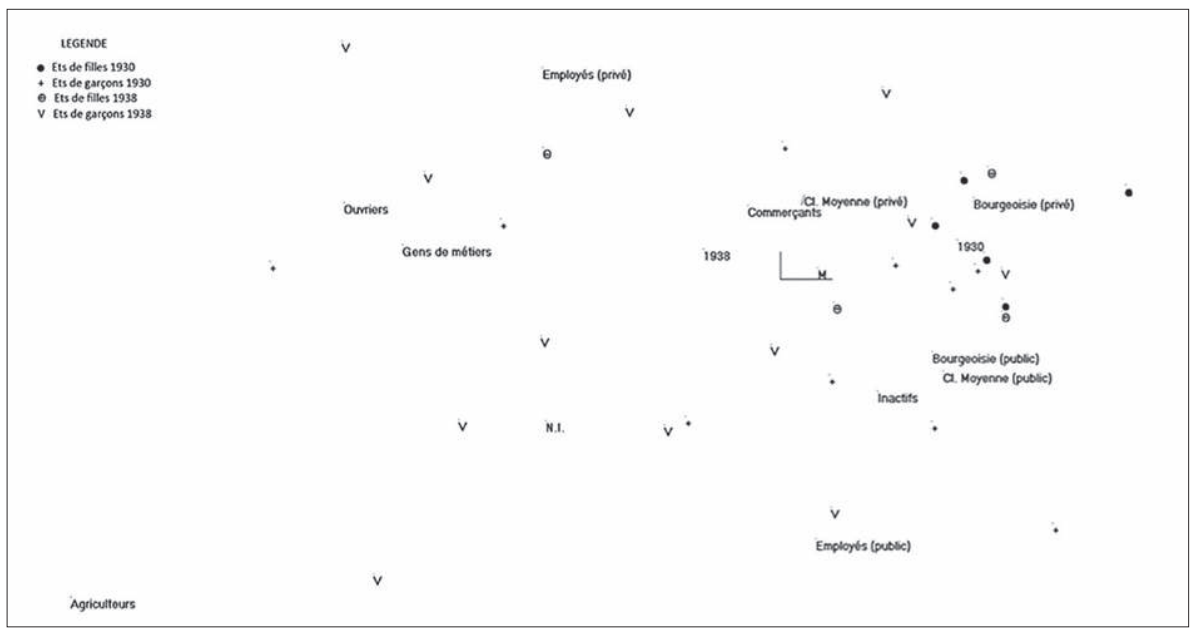

Graphique 9 : établissements selon le sexe et l'origine sociale des élèves

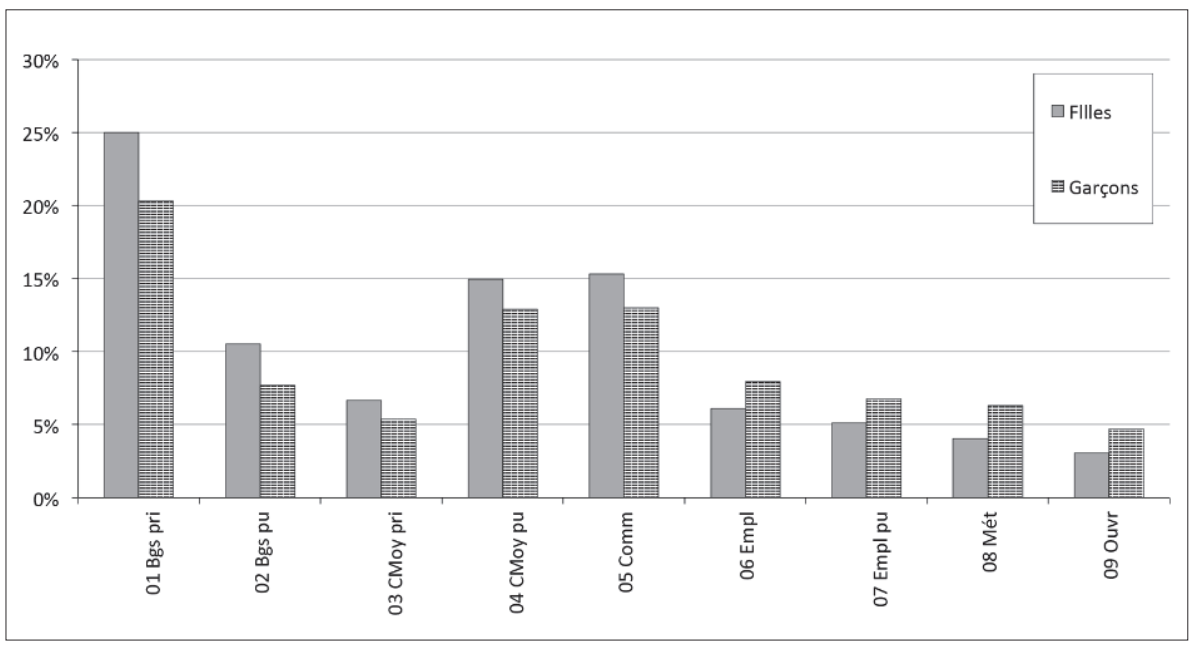

Graphique 10 : importance des divers groupes sociaux dans les établissements de filles et de garçons 
à la petite taille de notre échantillon, mais c'est peu probable. Nous avons en effet exclu ici de l'analyse le lycée de filles de Lille, pour lequel nous ne disposons de données qu'en 1934, or c'est, avec celui de Bordeaux en 1929, le plus bourgeois de tous ${ }^{27}$. La différence entre les deux sexes apparaît clairement à l'analyse factorielle. Si on lui soumet les 31 établissements-années de notre échantillon classés selon le poids relatif des catégories sociales, on obtient le graphique 9 : tous les établissements féminins sauf le collège de Saint-Quentin en 1937, se trouvent dans la partie droite du graphique. Or ce premier axe oppose clairement le peuple à la bourgeoisie ${ }^{28}$.

On peut préciser cette différence en examinant le poids des divers groupes sociaux dans l'ensemble de notre échantillon sans tenir compte des évolutions possibles entre le début et la fin de la période. Dans les établissements féminins, toutes les classes supérieures et moyennes de la société pèsent davantage que dans les établissements masculins. L'écart est de cinq points pour le groupe le plus importants, celui de la bourgeoisie du secteur privé. Inversement les employés, les gens de métier et les ouvriers, de toute façon peu présents, le sont moins dans les établissements féminins, comme le montre le graphique 10. La différence est faible, mais elle est nette.

Elle ne concerne pas également l'ensemble de la scolarité. Si l'on compare la sociologie des trois niveaux, élémentaire, premier et second cycles dans les établissements masculins et féminins, le second cycle présente quelques singularités (voir tableau $\mathrm{V}$ en annexe). Alors qu'aux deux premiers niveaux, la bourgeoisie privée pèse cinq points de plus chez les filles que chez les garçons, au troisième, ceux-ci l'emportent. En revanche, la bourgeoisie du secteur public est un peu plus présente chez les filles que chez les garçons aux deux premiers niveaux, mais au troisième elle pèse deux fois plus chez les garçons (voir le tableau 4). L'alignement des lycées de filles sur ceux de garçons, qui s'achève en 1930, n'a pas encore entraîné celui des usages sociaux, qui subissent l'influence des traditions du début du siècle. On se contente encore souvent dans la bonne bourgeoisie d'une scolarité secondaire raccourcie pour les filles, mais il en va tout autrement dans cette partie minoritaire de la bourgeoisie constituée par les fonctionnaires supérieurs, parmi lesquels on a classé les professeurs; ici, il est normal de conduire les filles jusqu'au baccalauréat.

$2742 \%$ d'élèves issues de la bourgeoisie à Bordeaux en 1929 et 40\% à Lille en 1934 .

28 Le premier facteur explique $30,6 \%$ de la variance, et le second $22 \%$. 


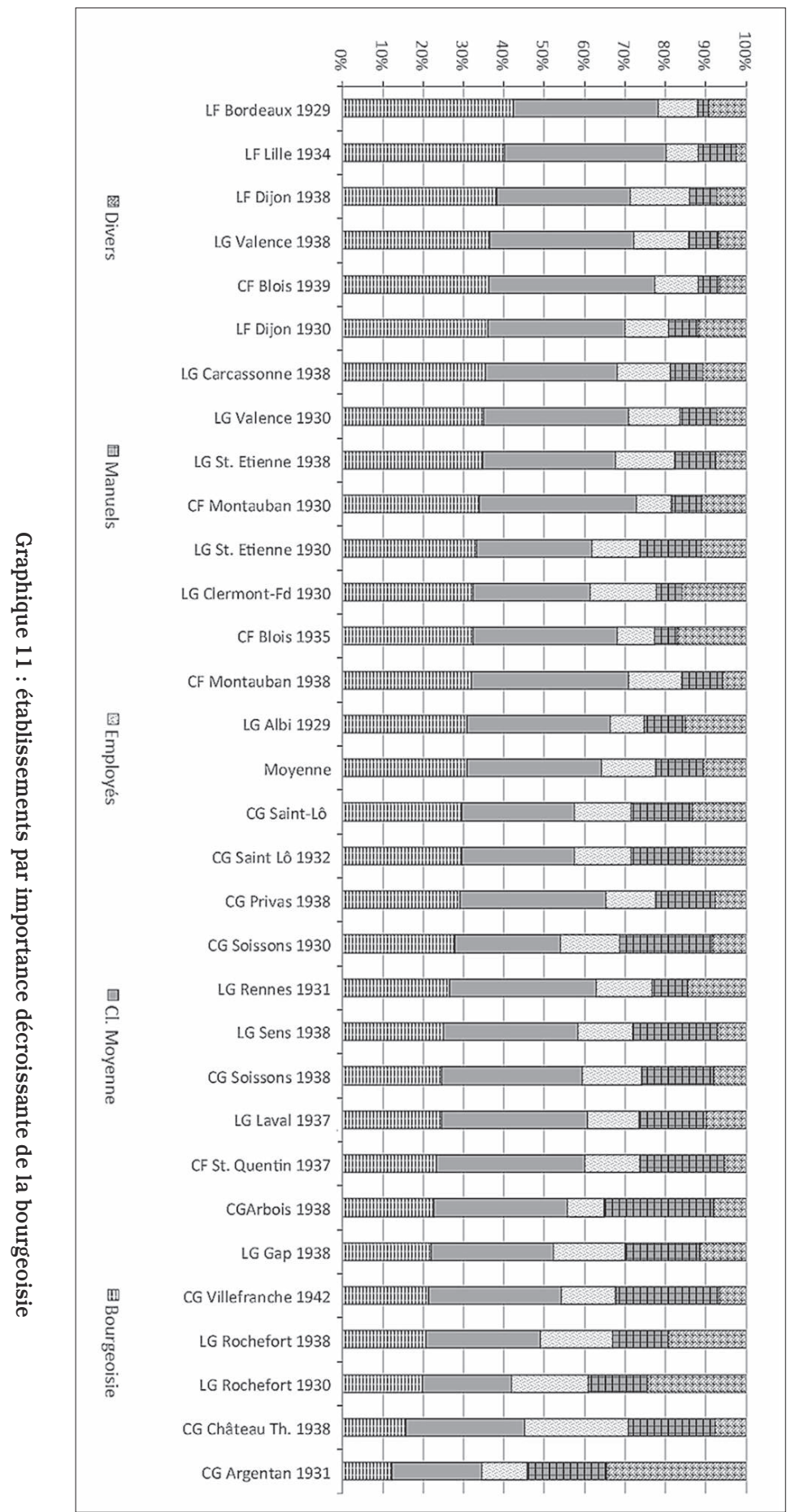


Alors que le poids de la bourgeoisie diminue régulièrement pour le secteur privé quand on passe des classes élémentaires au second cycle, perdant un peu plus de 4 points, pour le secteur public, moins étoffé, il passe de 8,5\% à $15,4 \%$ du premier au second cycle. Les comportements des deux milieux sont assez contrastés.

Pour expliquer ces différences entre filles et garçons, on pourrait faire appel à la concurrence de l'enseignement privé. Il ne faut jamais oublier, en effet, qu'ils soumettent les établissements publics à une très rude concurrence, sur laquelle, du fait de la loi de 1905, nous ignorons tout, sauf que, pour les garçons, le secteur privé scolarise autour d'un élève sur deux. Or il est très probable que le recrutement social des collèges privés soit plus élevé que celui des établissements publics et leur niveau scolaire inférieur, en particulier pour les filles, ce qui conduirait les parents les plus sensibles au niveau d'instruction à confier celles-ci plutôt aux établissements publics. Mais nous n'avons aucun moyen de valider cette hypothèse.

Une seconde explication, moins hypothétique, fait intervenir la différence de taille et d'implantation des deux réseaux secondaires publics, celui des garçons et celui des filles. Plus récent et moins dense, ce dernier concerne moins de petites villes que celui-là. Or, nous le verrons plus loin, pour des raisons évidentes, les établissements secondaires ont un recrutement moins élitiste dans les petites villes que dans les grandes : il leur faut attirer des élèves, et la bourgeoisie locale n'est pas assez étoffée pour remplir leurs classes, comme le montre le graphique 11, pour les besoins duquel nous avons construit une catégorie de "manuels" qui regroupe les agriculteurs, très peu nombreux car les établissements ne sont pas facilement accessibles à leurs enfants, les ouvriers proprement dits, et les "gens de métier".

Les établissements féminins sont dans la première partie du graphique, mais les lycées avant les collèges. Quant aux établissements masculins, on trouve en tête les lycées de Valence, Carcassonne, Saint-Étienne et Clermont, une hiérarchie que modifierait la prise en compte des classes moyennes.

Mais la différence entre établissements de l'un et l'autre genre n'est pas le seul trait que met en évidence le graphique 11, ni même le plus important. Il montre d'abord l'ampleur des différences sociologiques entre établissements (voir le tableau IV en annexe). L'enseignement secondaire n'est pas uniformément bourgeois. On y trouve des lycées presque totalement dédiés aux classes moyennes (commerçants inclus) et supérieures : les lycées de filles 
de Bordeaux et de Lille recrutent en leur sein $80 \%$ ou plus de leurs élèves. À l'autre extrémité, les établissements masculins de Rochefort, Gap ou ChâteauThierry en ont moins de $50 \%$. Symétriquement, le recrutement populaire est très variable. Les enfants d'agriculteurs n'ont d'importance significative qu'au minuscule collège d'Arbois - ce sont des viticulteurs - et au Lycée de Gap, du fait de l'école d'agriculture d'hiver. Nulle part ailleurs ils n'atteignent 10\% de l'effectif. Les fils d'ouvriers non qualifiés et manœuvres ne pèsent 10\% qu'au collège de Soissons, mais si on leur ajoute ceux des gens de métier, on atteint $22 \%$ de l'effectif à Villefranche, $17 \%$ ou un peu plus à Château-Thierry ou à Soissons en 1930 comme en 1938, et 14 à 15\% à Saint-Lô, Argentan, SaintÉtienne en 1930 et Laval en 1937, ce qui s'explique évidemment par la présence de classes primaires supérieures à Villefranche, Château-Thierry et Soissons.

Jusqu'ici, nous avons considéré la période dans son ensemble. Du fait de l'hétérogénéité des établissements de l'échantillon, nous avons suspendu l'examen d'une éventuelle démocratisation de leur recrutement sous l'effet de la croissance des effectifs. Nous pouvons maintenant la reprendre, en réduisant l'examen aux quelques établissements pour lesquels nous disposons de données à la fois en début et en fin de période ${ }^{29}$.

\section{L'enseignement secondaire s'est-il démocratisé dans les années 1930 ?}

Le moins qu'on puisse dire, est que la situation n'a guère évolué. Comme l'analyse porte sur des effectifs restreints, surtout pour les établissements féminins en début de période, nous devons rester prudents. Mais les changements restent fort limités, comme le montre le graphique 12, où nous avons distingué établissements de filles et de garçons.

Il semble que les bénéficiaires de la croissance aient été surtout les enfants de cadres moyens et commerçants. Chez les garçons, les gains de la bourgeoisie du secteur privé sont compensés par le recul du secteur public. Chez les filles, la bourgeoisie recule de quelques points, ainsi que les inactifs; les gains sont pour les commerçants, et un peu plus pour les employés, les gens de métier et les ouvriers, mais à des niveaux très faibles. Chez les garçons, le secteur privé

29 Les aléas de conservation des registres créent des effets de sources insurmontables. La base comprend peu d'établissements pour lesquels les données soient disponibles en début et en fin de période : trois établissements féminins, le lycée de Dijon, le collège de Montauban et le cours secondaire de Blois pour lequel les seules données concernent 1935 et 1939, soit 838 et 1593 élèves; cinq établissements masculins, les lycées de Saint-Étienne, Valence et Rochefort et les collèges de Soissons et de Privas, soit 2008 et 2856 élèves. 


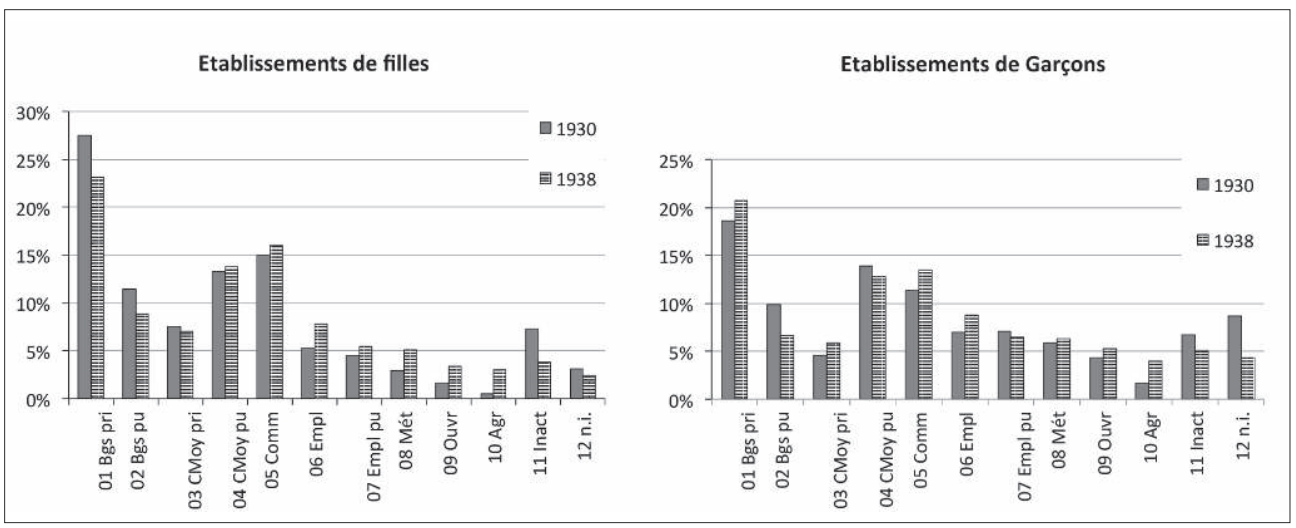

Graphique 12 : sociologie des établissements de filles et de garçons en début et en fin de période

progresse, dans la bourgeoisie, les classes moyennes, le commerce et les employés, comme s'il avait souffert de la crise économique en début de période et avait donc un handicap à remonter, tandis que le secteur public, moins atteint par la crise, n'aurait pu progresser comme lui. Les gens de métier et les ouvriers gagnent un point ou deux mais restent autour de $5 \%$. Il s'en faut de beaucoup que la croissance des années trente ait bouleversé la structure sociale des établissements. Elle l'a modifiée, et légèrement démocratisée, mais à la marge.

Une analyse plus fine, selon les trois niveaux de la scolarité, apporte quelques précisions (voir le tableau V, en annexe). Pour les garçons, les classes élémentaires - qui n'ont pas été rendues gratuites par la loi de 1930 - enregistrent une progression de toutes les classes supérieures et moyennes, de statut public ou privé. Elle est de 8 points. Pour les filles, il en va de même, sauf en ce qui concerne la bourgeoisie du secteur public, qui est stable, et les cadres moyens du secteur privé, qui reculent de 2 points. Mais la bourgeoisie du secteur privé gagne 8 points chez les garçons et plus de 6 chez les filles. L'évolution est d'autant plus intéressante que l'importance relative des petites classes, qui restent payantes, recule du fait de la croissance du secondaire proprement dit. Faut-il y voir un effet de la crise économique? Ou la fin de l'élargissement du recrutement provoqué par la crise démographique? Les familles auraient-elles craint davantage la promiscuité avec les élèves de la communale et renforcé leurs stratégies de distinction?

Dans le premier et le second cycle, l'évolution est différente dans les établissements féminins et masculins. On constate dans les lycées et collèges de filles une 


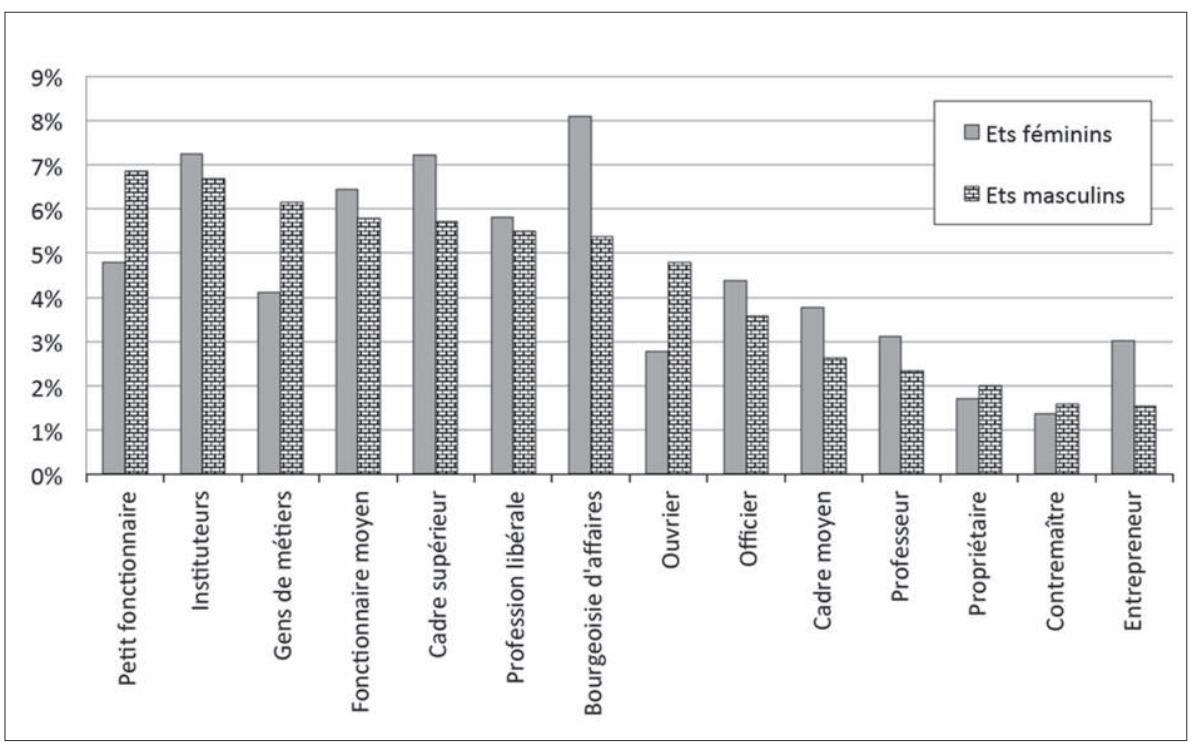

Graphique 13 : importance de quelques professions parmi les parents d'élèves des établissements masculins et féminins pendant les années 1930

progression sensible des classes moyennes, des commerçants et des employés du secteur privé dans le premier cycle, alors que dans le second, ils reculent un peu, les employés seuls enregistrant une progression de trois points quel que soit le secteur. Un résultat qui confirme l'intérêt des classes moyennes pour des scolarités secondaires incomplètes quand il s'agit des filles. Pour les garçons, les résultats sont plus difficiles à interpréter : dans les deux cycles, les progrès de la bourgeoisie du secteur privé sont compensés par un recul identique de quatre points du secteur public. Il semblerait que les professeurs, officiers, magistrats et autres fonctionnaires supérieurs aient eu depuis longtemps l'habitude de mettre leur fils au lycée. Le secondaire pouvait donc difficilement élargir son recrutement dans ce milieu, et la croissance des années trente aurait donc entraîné son recul relatif. Inversement, un recrutement en hausse dans la bourgeoisie du secteur privé, dans ce contexte de croissance, atteste une attractivité intéressante, dont on regrette de ne pouvoir dire si elle traduit un déplacement des collèges confessionnels vers les établissements de l'État, ou un développement des scolarités secondaires dans un milieu de négociants et d'entrepreneurs qui pourraient accorder davantage d'intérêt aux études conduisant au baccalauréat. 
Mais cette analyse est trop globale, et elle ne permet pas d'apprécier la mixité sociale relative de l'enseignement secondaire. Que sont cette bourgeoisie et ces classes moyennes? Le graphique 13 permet d'apprécier le poids relatif de certaines professions dans les établissements féminins et masculins. Portant sur plus de $60 \%$ des 15300 lycéen(ne)s de la base de données, Il révèle à la fois une tendance générale et des différences sensibles.

Quel que soit le genre, impossible de ne pas remarquer le poids des fonctionnaires : les enfants d'instituteurs sont plus nombreux que ceux des membres des professions libérales, alors que les deux groupes sociaux ont à peu près les mêmes effectifs dans la population totale ${ }^{30}$, et que les ménages dont le chef est un instituteur sont certainement moins nombreux du fait de l'endogamie professionnelle. Il nous faudra examiner plus loin dans quelle mesure la présence en force des enfants de fonctionnaires et d'instituteurs est l'effet des avantages consentis par l'État à ses serviteurs. Il reste que l'image d'Épinal d'un secondaire dominé par la bourgeoisie libérale ne cadre pas avec les résultats de l'enquête. C'est le moment de rappeler que la moitié du secondaire lui échappe : les établissements privés, confessionnels pour la plupart, dont la clientèle est très probablement moins démocratique.

Second trait digne d'intérêt, les milieux économiques, bourgeoisie d'affaires, entrepreneurs, cadres supérieurs et moyens du secteur privé, sont mieux représentés dans les établissements féminins que masculins. Cette différence est difficile à expliquer. L'analyse résumée par le graphique 13 portant sur plus de $60 \%$ des 15300 élèves de la base de données, on peut exclure qu'elle soit le contrecoup de changements survenus dans d'autres milieux professionnels. On serait tenté d'y voir un effet de réseau : les lycées et collèges de filles, plus récents, moins nombreux, situés dans des villes plus importantes, bénéficieraient d'une clientèle potentielle plus étoffée dans ces milieux. Le même phénomène ne jouerait pas pour les professions libérales, à une époque où tout canton compte notaire, médecin et pharmacien.

Un autre résultat vient conforter cette explication : l'avantage des établissements masculins dans les classes inférieures de la société. Certes le poids des ouvriers y reste dérisoire : 4,8\%. C'est cependant plus que celui des officiers

30 Au recensement de 1936, 58119 professions judiciaires (avocats, avoués, huissiers, notaires), 82848 professions médicales (médecins, pharmaciens, dentistes, vétérinaires), 13655 architectes, soit un total de 154622 personnes, contre 151341 instituteurs et institutrices dans les écoles primaires (maternelles et primaire supérieur exclus) en 1938-1939. 
ou des professeurs, et deux fois plus que dans les établissements féminins. Surtout, il faut compter avec ceux que nous avons appelés les gens de métier, artisans ou salariés suivant les lieux et les moments, qui dépassent $6 \%$, et les petits fonctionnaires (facteur, cantonnier, etc.) qui frôlent les $7 \%$. Au total près de $18 \%$, contre $11,7 \%$ dans les établissements féminins.

Ces résultats posent toute la question du rôle de l'enseignement secondaire, et de sa diversité interne dans la promotion sociale des enfants du peuple.

\section{Sociologie du classique et du moderne}

L'enseignement secondaire comporte de la sixième aux classes terminales exclues deux filières qui se distinguent par l'enseignement du latin. La filière classique est la filière noble : c'est la plus ancienne, et il faut attendre 1902 pour que le baccalauréat moderne soit mis à parité avec le classique. Les registres, qui prennent les sections classiques avant les sections modernes, respectent cette hiérarchie que confirme l'ordre alphabétique de leur désignation (A puis B). C'est donc la filière que privilégient les établissements secondaires. Dans l'ensemble de notre base de données, $62 \%$ des élèves de la sixième à la première sont en section classique.

Cette moyenne est évidemment trompeuse, car elle englobe les établissements féminins. Or la loi de 1880 avait exclu le latin de leurs programmes et ils ont commencé à ouvrir des cours facultatifs de latin, confiés à des professeurs d'établissements masculins, au début du siècle seulement. En 1924, l'enseignement des filles a été aligné sur celui des garçons, mais la mise en œuvre de cette mesure n'a pas été étudiée jusqu'ici. Elle s'est faite progressivement, avec l'ouverture de sections classiques en sixième d'abord, puis en cinquième l'année suivante et ainsi de suite. Le baccalauréat est devenu la sanction normale des études, mais beaucoup d'établissements ont continué à préparer leurs élèves au diplôme de l'enseignement secondaire féminin créé par la loi Sée de 1880. Il y a donc moins de latinistes dans les établissements de filles que de garçons : dans notre échantillon, l'écart est de 17 points : $51 \%$ contre $68 \%$. Si les lycées de Bordeaux ou de Dijon semblent avoir achevé leur mutation, tout en conservant quelques classes "ancien régime", le collège de Montauban n'a encore aucune section classique en 1930, et, en lieu et place d'une classe de première, entre la seconde et la philosophie, une section "BS" prépare au brevet supérieur, un 


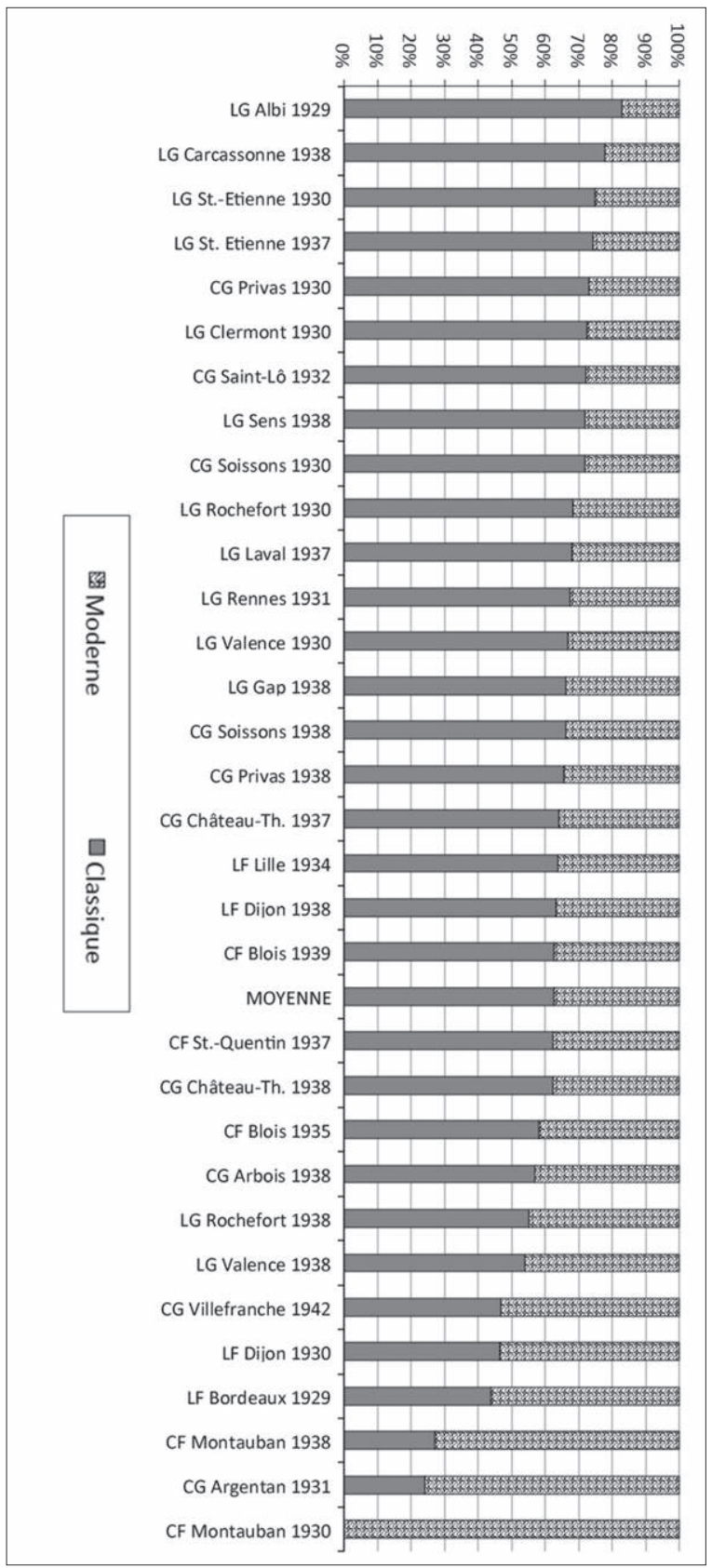


diplôme de l'enseignement primaire qui permet de devenir institutrice ${ }^{31}$. Une situation qui va évoluer naturellement, avec un décalage suivant l'importance des villes : en 1938, le collège de Montauban compte un quart de latinistes et leur importance au lycée de Dijon passe de 45 à $63 \%$ au cours des années trente. Un niveau auquel se trouve également le cours secondaire de jeunes filles de Blois : $63 \%$, malgré son statut obsolète.

La plupart des établissements masculins comptent entre 50 et $70 \%$ de latinistes. Certains sont presque exclusivement classiques, comme le lycée d'Albi en 1929, avec $82 \%$ de latinistes, suivi à $78 \%$ par celui de Carcassonne en 1938. Les collèges font souvent au moderne une place plus large : un bon tiers (Soissons et Privas en 1938), voire un peu plus de la moitié (Villefranchesur-Saône en 1942). Deux lycées de notre échantillon font exception : celui de Valence, avec 46\% de "modernes" en 1938, et surtout celui de Rochefort, un lycée atypique qui ne se contente pas de développer, comme on l'a vu, d'importantes sections d'enseignement primaire supérieur, mais fait une large place aux sections modernes, autour de $45 \%$ en début comme en fin de période. La diversité des établissements secondaires publics ne laisse pas de surprendre.

La sociologie des élèves confirme cette diversité. Il est deux façons de l'apprécier. On peut s'interroger sur le poids des divers milieux parmi l'ensemble des latinistes, mais l'on peut aussi examiner le poids des latinistes parmi les élèves des divers groupes sociaux. Les deux indicateurs donnent des aperçus complémentaires, mais le second, reposant sur des effectifs moindres, est plus fragile. C'est pourquoi nous avons exclu de l'analyse les établissements les plus petits. D'autre part, compte tenu des difficultés de l'étude, nous ne l'avons menée que sur dix-huit établissements, soit plus de la moitié de notre échantillon, mais qui regroupent entre les deux-tiers et les trois-quarts des élèves susceptibles de faire ou non du latin ${ }^{32}$.

Si l'on regarde la composition sociale des différentes filières (tableau VI en annexe) la bourgeoisie du secteur privé représente près du quart des élèves dans

31 Ce diplôme est requis réglementairement des instituteurs et institutrices à partir de 1932, mais la plupart le possédaient déjà car les écoles normales y préparaient leurs élèves.

32 Exactement 6880 élèves sur 9615, soit 71,5\%. Pour cette étude, nous ne dissocierons pas les filles des garçons. Les statistiques par milieux sociaux sont effet très semblables, les corrélations étant bonnes au début de la période et s'améliorant en fin de période (respectivement 0,79 et 0,91) pour être, dans l'ensemble, très satisfaisantes $(0,92)$. Il n'y a qu'une exception : les filles de propriétaires, dont un peu plus de $20 \%$ font du latin, contre plus de $6 \%$ leurs frères. Elle s'explique sans doute parce que, chez ces rentiers, il n'est pas question qu'elles aient plus tard une situation. 
le classique comme dans le moderne; en revanche, celle du secteur public pèse beaucoup plus dans le classique $(18,8 \%)$ que dans le moderne $(11,9 \%)$ où les enfants d'employés du secteur privé viennent en second rang (16,3\%) alors qu'il ne représentent que $12 \%$ des latinistes. Dans l'ensemble, les enfants du secteur public constituent plus du tiers de l'effectif des sections classiques (34,3\%) et le quart de celui des sections modernes $(24,5 \%)$. Les sections "autres" qui regroupent les classes proprement primaires supérieures quand elles existent et les anciennes sections de l'enseignement secondaire féminin qui conduisaient au diplôme ou au brevet supérieur, concernent les fils et filles des gens de métier $(13,7 \%)$, de la classe moyenne du secteur privé $(13,4 \%)$, d'inactifs et d'employés du secteur public. On est loin de la démocratisation; la domination de la bourgeoisie et des classes moyennes est évidente, mais une certaine mixité sociale existe néanmoins. Les enfants d'ouvriers, d'employés, d'agriculteurs et de gens de métier représentent $30 \%$ de l'effectif des sections classiques et 35,7\% de celui des sections modernes.

Si l'on examine maintenant le comportement des divers groupes sociaux quant aux scolarités de leur progéniture, les contrastes sont plus accentués (tableau VII en annexe). Le graphique 15 représente l'importance décroissante que les divers groupes sociaux accordent au classique. En règle générale - et ceci résulte en grande partie de l'offre d'enseignement des établissements - le classique attire toujours plus que le moderne, mais ces deux filières proprement secondaires doivent compter avec les filières "autres" qui concernent principalement les enfants des milieux les moins favorisés, mais ne l'emportent que chez les ouvriers. Très fortes chez les agriculteurs, les gens de métier, elles laissent pourtant une large place aux filières modernes et même classiques. Chez les employés du secteur privé, l'effectif du classique est même le double de la filière primaire supérieure.

La filière classique l'emporte de très loin dans les classes moyennes et la bourgeoisie du secteur public. Celles du secteur privé lui donnent encore une très large préférence, mais la filière moderne y recrute proportionnellement davantage. Ces quatre groupes sociaux sont au-dessus de la préférence moyenne pour le classique. Les autres filières, qui constituent on l'a vu une extension accessoire, limitée à certains établissements, ne l'emportent jamais, sauf chez les ouvriers. Le choix du lycée répond manifestement à une volonté de promotion sociale, et celle-ci passe par le classique plus que par le moderne.

Mais les groupes sociaux que nous avons déterminés constituent des agrégats composites, et l'analyse de groupes plus limités met en évidence des comportements 


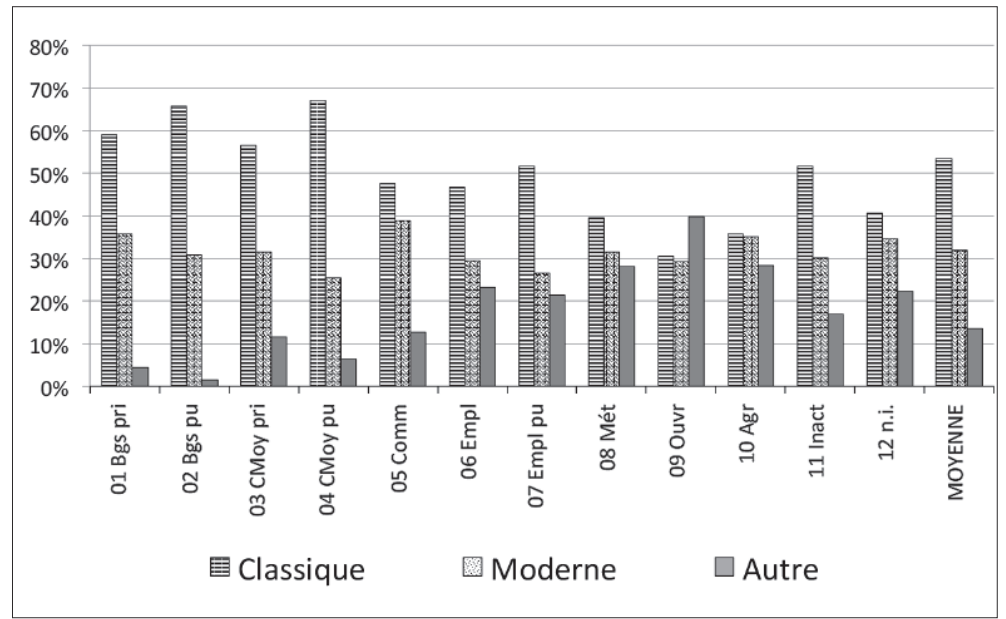

Graphique 15 : importance des différentes filières selon les groupes sociaux

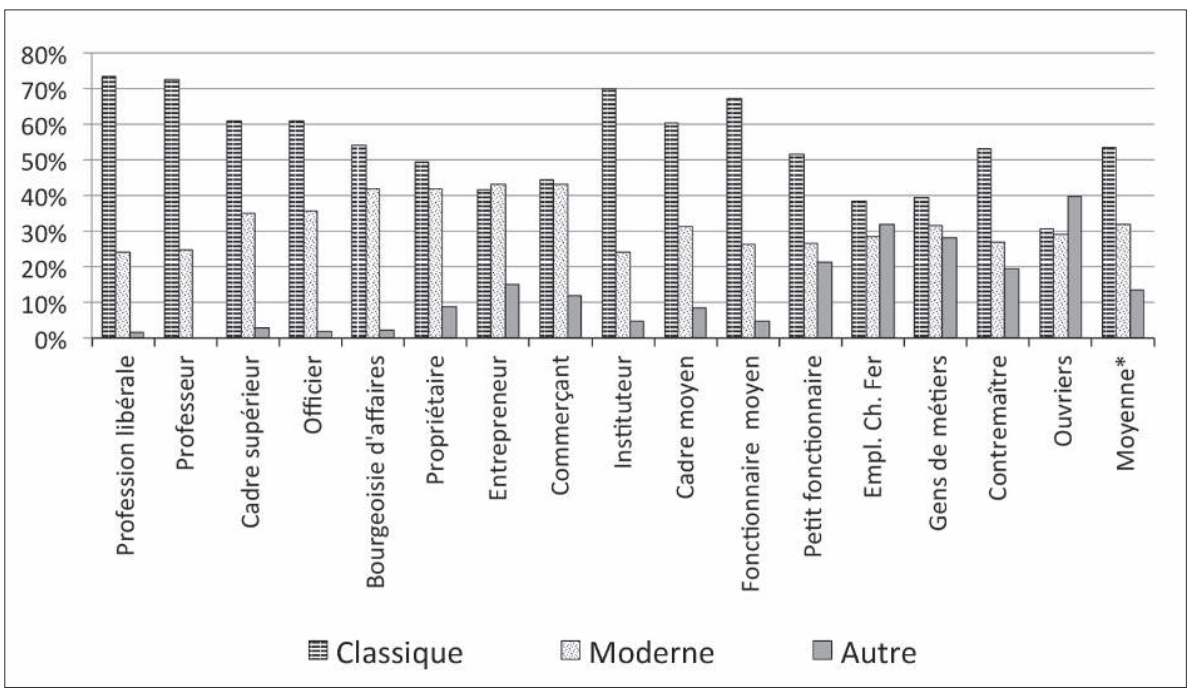

Graphique 16 : importance des différentes filières pour quelques professions 
plus différenciés encore. Nous avons analysé une quinzaine d'entre eux, en ne retenant que des professions pour lesquelles un effectif suffisant permettait des résultats relativement solides (tableau VIII en annexe). Ils sont intéressants.

Les groupes les plus désireux de faire faire à leurs enfants des études classiques sont en effet les professions libérales et les professeurs du secondaire ou du supérieur, suivis de très près par les instituteurs, les cadres moyens du secteur privé et les fonctionnaires intermédiaires (percepteur, etc.). Plus des deux-tiers, et près des trois-quarts parfois, font faire du latin à leurs rejetons. Les sections modernes en attirent péniblement près du quart seulement, les autres sections n'accueillant qu'un résidu.

Le comportement des instituteurs mérite une attention particulière car leurs enfants sont plus nombreux dans le secondaire que ceux de toute autre profession : on en dénombre 769 parmi les élèves de la sixième à la première toutes sections confondues, soit un élève sur $12(8 \%)$, mais avec une différence sensible selon le sexe : 9,2\% pour les filles contre seulement 7,4\% pour les garçons. Manifestement, les instituteurs tiennent beaucoup plus que d'autres à faire faire des études secondaires à leurs filles, et l'on n'a pas tenu compte, dans ce dénombrement, des 4 enfants dont le père exerçait une autre profession mais dont la mère était institutrice. Il s'agit majoritairement d'études classiques : les deuxtiers $(65,8 \%)$ des filles d'instituteurs font du latin, et une latiniste fille sur huit a un père maitre d'école ${ }^{33}$. C'est un comportement plus favorable au classique que dans l'ensemble du secondaire féminin. Pour leurs fils, les instituteurs choisissent encore plus le latin : 73,2\% d'entre eux sont dans les sections classiques, si bien qu'ils représentent $9,6 \%$ des élèves de ces sections. Il y a là comme un plébiscite en faveur des humanités classiques qui retire beaucoup de leur crédibilité aux plaidoyers pour les humanités modernes et l'enseignement primaire supérieur. Dans le conflit récurrent qui oppose depuis la fin du XIX ${ }^{e}$ siècle l'ordre primaire et l'ordre secondaire, la supériorité que les membres du premier reconnaissent au second quand il s'agit de leurs enfants constitue un handicap décisif.

Les cadres supérieurs (secteur privé) et les officiers semblent un peu plus favorables aux sections modernes qui accueillent le tiers de leurs enfants, mais les milieux d'affaires sont plus partagés. De la bourgeoisie d'affaire (négociants, etc.) aux entrepreneurs et aux commerçants, en passant par les propriétaires, le pourcentage d'élèves en section moderne s'élève et finit même, chez les

33 Ou une mère quand elle est seule mentionnée. 
entrepreneurs et les commerçants, par faire jeu égal avec celui des sections classiques. Le monde de l'argent ne partage pas tout à fait la révérence des enseignants, des fonctionnaires et des professions libérales pour le latin. $\mathrm{Si}$ l'on veut présenter les humanités classiques comme la culture de la classe dominante, il convient de tenir compte de ces nuances.

D'autant que l'attraction du classique semble très forte dans certains groupes plus populaires : les contremaitres par exemple, ou les petits fonctionnaires. Ici, l'enseignement classique compte encore deux fois plus d'élèves que le moderne. À y regarder de plus près, il ne s'agit pas des plus petits fonctionnaires, mais de ceux qui amorcent une promotion sociale. Les gendarmes par exemple : sur 29 fils de gendarme, 18 font du latin ${ }^{34}$, ou encore les employés de mairie, dont 5 enfants sur 9 suivent la filière classique. Le cas des enfants d'employés des postes est éloquent : les enfants de simples facteurs font du latin moins d'une fois sur trois; s'il s'agit de facteurs-receveurs, qui ne font pas les tournées et ont une responsabilité, c'est le cas une fois sur deux. Pour les employés sans autre indication (s.a.i.), la proportion est un peu supérieure $(57,6 \%)$, mais ce sont les deux-tiers pour les enfants de commis et de rédacteurs, et les troisquarts pour ceux de rédacteurs principaux.

\begin{tabular}{l|c|c|c|c|c|c}
\hline & Facteur & $\begin{array}{c}\text { Facteur- } \\
\text { receveur }\end{array}$ & $\begin{array}{c}\text { Employé } \\
\text { s.a.i. }\end{array}$ & Commis & Rédacteur & $\begin{array}{c}\text { Rédacteur } \\
\text { principal }\end{array}$ \\
\hline Effectif & 45 & 12 & 59 & 15 & 18 & 8 \\
\hline $\begin{array}{l}\text { Dont } \\
\text { classique }\end{array}$ & 13 & 6 & 34 & 11 & 12 & 6 \\
\hline
\end{tabular}

Tableau 4 : enfants de diverses catégories d'employés des PTT dans les sections classiques

Si l'on regroupe ces différentes observations, l'enseignement classique est assez différent des représentations courantes. On en fait la culture des classes dominantes, ce qui n'est pas faux, et le serait sans doute encore moins pour les établissements privés. Mais cette représentation est trop simple. D’une part, elle ne tient pas compte des différences internes aux classes dominantes : quand leur supériorité tient à l'argent, elles font moins de cas des humanités traditionnelles que quand elle tient à la parole et au savoir. D’autre part et surtout, elle oublie complètement l'importance des classes moyennes en voie d'ascension sociale, et notamment des multiples fonctionnaires qui leur envoient des

34 Mais 3 filles sur 9 seulement. 
cohortes d'élèves. L'enseignement secondaire public est plus encore un facteur de promotion que de reproduction sociale.

La question qui se pose à ce stade est alors de savoir s'il s'agit là d'un fonctionnement de fait ou d'une politique.

\section{Le choix des boursiers}

L'État, en effet, facilite aux élèves de certaines familles l'accès à l'enseignement secondaire grâce à des aides diverses. Il accorde par exemple depuis le $\mathrm{XIX}^{\mathrm{e}}$ siècle la remise des droits universitaires, c'est-à-dire des frais d'inscription, aux enfants d'instituteurs et de professeurs. Tous les établissements ne mentionnent pas ces divers soutiens dans leurs registres, car ils n'en avaient pas l'obligation. Cependant notre échantillon nous renseigne sur 7745 élèves dans 13 lycées et collèges, ce qui permet quelques observations ${ }^{35}$.

Ces remises universitaires primaires ou secondaires (RUP ou RUS) pouvaient constituer une aide non négligeable en début de période, mais la gratuité leur a fait perdre leur raison d'être. Pourtant on en trouve encore quelques-unes en fin de période. Sur 500 remises (334 RUP et 166 RUS), 104 seulement concernent 1937-1938. Il s'agit souvent d'élèves de classes devenues gratuites, ce qui surprend un peu, mais au lycée de filles de Dijon uniquement d'élèves des classes primaires qui sont restées payantes, ce qui représente assez peu, 270 francs, et ne bénéficie pas nécessairement aux plus pauvres, car on trouve cinq professeurs de faculté parmi les bénéficiaires ${ }^{36}$. Dans quelques cas, les remises se cumulent avec des bourses. Comme seuls les enseignants peuvent en bénéficier, cela constitue pour eux une incitation qui explique peut-être en partie la forte présence des enfants d'instituteurs dans l'enseignement secondaire, bien que, pour des raisons que nous n'avons pas éclaircies, tous n'en bénéficient pas. Serait-ce parce qu'ils ne l'ont pas demandée? Néanmoins 277 enfants d'instituteurs de cet échantillon sur 569 en bénéficient, une proportion analogue à celle des enfants de professeurs (107 sur 222).

35 Ce sont les lycées de garçons d'Albi en 1929, Clermont-Ferrand en 1930, Saint-Étienne en 1937, Carcassonne et Gap en 1938, les lycées de filles de Bordeaux en 1929, Lille en 1934, Dijon en 1938, les collèges de garçons de Soissons en 1930 et Château-Thierry en 1937-1938, et les collèges de filles de Montauban en 1930 et Blois en 1935 et 1939.

36 La RUS est considérée comme un droit par les professeurs de lycées et d'université. La circulaire du 14 juin 1895 qui a tenté de la supprimer a suscité une opposition si forte que le gouvernement y a renoncé. Yves Verneuil, Corporatisme, amicalisme et syndicalisme. La représentation des professeurs de lycée (1880-1940), Mémoire d'habilitation, université de Paris-Sorbonne, 2015, vol. 1, p. 260. 
Nous n'étudierons pas le cas particulier des 186 pupilles de la nation de notre échantillon renseigné. Ils sont relativement nombreux - 150 soit $6 \%$ des élèves - au début des années trente, pour des raisons démographiques évidentes, auxquelles s'ajoute l'attention que leur accorde l'Office des pupilles. On ne s'étonnera pas de leur forte présence parmi les enfants de femmes seules à cette époque : $26,1 \%$ soit un sur quatre. Les deux-tiers d'entre eux bénéficient d'une bourse nationale.

Les bourses de toute nature, principalement nationales, mais aussi parfois départementales et exceptionnellement collégiales peuvent se cumuler (65 cas) et il est difficile d'évaluer leur importance. Le cahier du lycée de filles de Dijon donne leur montant, mais il varie beaucoup, de 1710 à 3960 francs pour les pensionnaires, et de 450 à 1800 pour les externes simples. La croissance des effectifs au cours des années trente ne s'est pas accompagnée d'une augmentation parallèle du nombre de bourses, si bien que la proportion de boursiers, qui était en début de période d'un élève sur cinq (20,3\%), n'est plus que d'un sur douze $(8,1 \%)$ en fin de période ${ }^{37}$. Elle varie d'ailleurs d'un établissement à l'autre sans que nous sachions pourquoi (annexe, tableau IX). Dans notre échantillon, en début de période, elle culmine au lycée de garçons de Clermont-Ferrand (24\%), celui d'Albi n'en comptant que 15,9\%. En 1934, le lycée de filles de Lille compte $10,9 \%$ de boursières, mais celui de Dijon n'en accueille que 3,3\%.

En fin de période, moins nombreuses, les bourses semblent destinées à favoriser l'accès au baccalauréat, car elles sont sensiblement plus nombreuses dans le second cycle que dans le premier. Au collège de Château-Thierry, comme au lycée de Gap, qui ont des classes primaires supérieures en 1938, les bourses vont également aux élèves de celles-ci : elles sont importantes pour l'équilibre financier de l'établissement auquel le ministère contribue ainsi indirectement. Mais qui en sont les bénéficiaires?

Première observation : les garçons bénéficient de bourses beaucoup plus souvent que les filles : on compte en moyenne pour la période et pour les classes secondaires, terminale exclue, $14,7 \%$ de boursières contre $26,5 \%$ de

37 Le phénomène a déjà été signalé par Jean-Michel Chapoulie, L'École d'Etat conquiert la France. Deux siècles de politique scolaire, Rennes, Presses universitaires de Rennes, 2010, p. 194-195. On comptait au maximum, atteint en 1932, 26,6\% de boursiers dans les classes secondaires et 13,7\% en 1938. Comme lui, nous avons exclu de ce calcul les quelques boursiers des classes élémentaires (56) et primaires supérieures (77). Nos chiffres sont inférieurs de 6 points, ce qui est beaucoup. Il est possible que les décisions d'octroi de bourses qui auraient été notifiées après le 5 novembre, date à laquelle les lycées transmettent les effectifs consignés dans leurs registres, n'aient pas été reportées sur ceux-ci. 


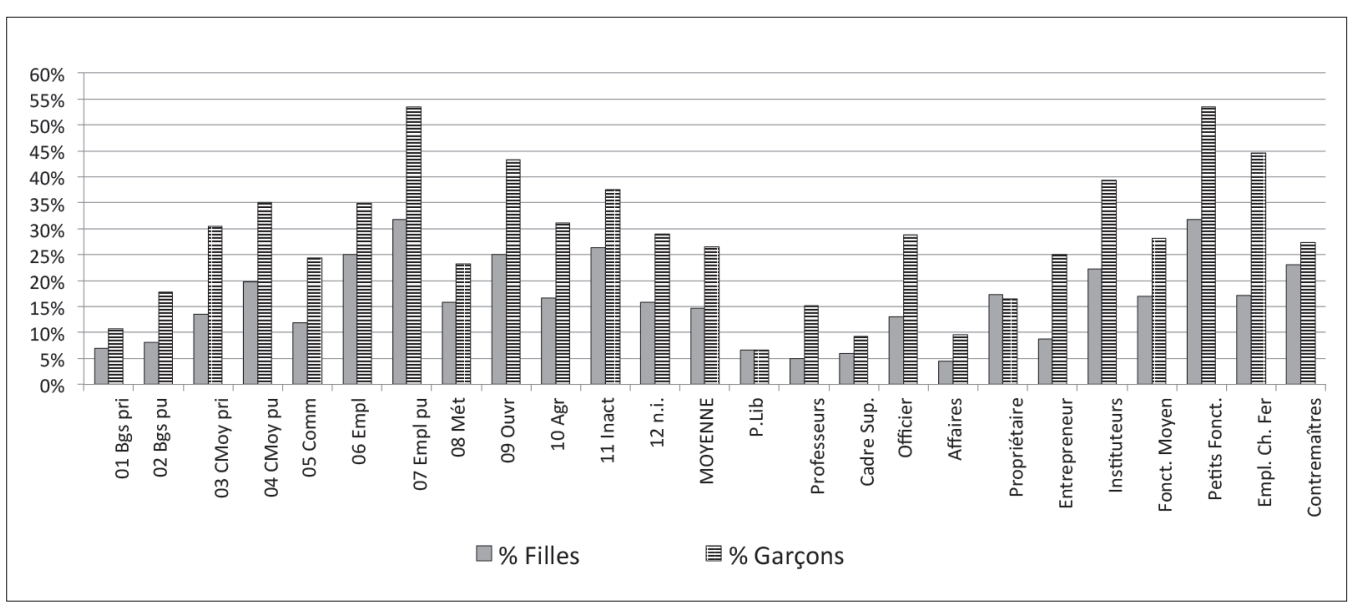

Graphique 17 : proportion de boursiers selon le milieu social et le genre

boursiers. En second lieu, les bourses vont un peu plus souvent aux élèves des sections classiques que modernes : $13,6 \%$ contre $11,1 \%$. Il est difficile dans ces conditions d'attribuer aux incitations du ministère le choix prioritaire des études classiques dans les groupes qui les privilégient.

Ce ne sont pas les enfants des classes supérieures de la société. Privée comme publique, la bourgeoisie ne bénéficie qu'exceptionnellement de bourses. Professions libérales, professeurs, cadres supérieurs comptent autour d'un boursier sur vingt élèves, et souvent moins. Seules exceptions, les filles de propriétaires ( $25 \%$ dans les sections classiques), probablement en raison du grand nombre de petits propriétaires dans cette catégorie. Chez les commerçants, on trouve un peu plus de boursiers : 10 à $12 \%$ dans les sections classiques. Mais les surprises sont ailleurs. On a souvent écrit que les bourses servaient à récompenser des fonctionnaires méritants : cela ne semble pas le cas des professeurs, et les cadres moyens du secteur public ne bénéficient guère plus des bourses que ceux du secteur privé. Les instituteurs comptent entre 15 et $20 \%$ de boursiers, avec un léger avantage pour les sections modernes, ce qui suggère que les bourses répondent ici à de réelles difficultés familiales; l'État ne semble pas pousser particulièrement les maîtres d'école à faire faire des études classiques à leurs enfants. Les vrais bénéficiaires des bourses appartiennent aux milieux qui en ont le plus besoin, et souvent pour des études classiques : les employés, les ouvriers, mais pas les gens de métier, les employés de chemin de fer, avec deux fois plus de bourses pour le classique que pour le moderne, 
et les petits fonctionnaires, auxquels il faut ajouter les femmes seules, souvent veuves de guerre. Dans ces milieux, on trouve autour d'un quart de boursiers.

\section{Conclusion}

$\mathrm{Au}$ terme de cette radioscopie, quel diagnostic d'ensemble formuler?

L'examen fait d'abord ressortir l'extrême diversité des établissements secondaires. C'est un résultat de la méthode que nous avons suivie : en analysant un ensemble d'établissements, nous nous donnions les moyens de mettre en évidence leurs différences. Elles sont pourtant plus accentuées que nous ne l'imaginions, et le réseau secondaire était avant 1940 probablement beaucoup plus hétérogène qu'aujourd'hui dans sa morphologie. Nous n'avons pas le moyen d'évaluer les différences de niveau ou de climat scolaire : l'anthropologie historique demande des sources qui font défaut. Mais sur toutes les dimensions que nous avons explorées, les différences sont fortes; elles concernent aussi bien la taille des établissements, que l'importance de l'internat, la proportion de boursiers, et le genre - une différence qui a disparu mais qui entraînait encore à la veille de 1940 des différences de scolarité. Le seul trait qui les unisse est la priorité qu'ils donnent aux humanités classiques, encore qu'il faille faire quelques réserves, pour les établissements féminins en début de période, et pour ceux qui accueillent des classes primaires supérieures, mais l'exemple de Château-Thierry montre qu'il s'agit de corps étrangers. En règle générale, partout les sections classiques sont plus étoffées que les sections modernes : le seul drapeau qu'on puisse faire flotter sur tous les établissements secondaires, c'est celui du latin.

Dans cette diversité, la plus frappante affecte ce que nous avons appelé les profils pédagogiques : les effectifs des différents niveaux et des différentes filières (graphiques 4). Certes, l'on retrouve généralement des traits communs, des classes de première plus étoffées que celles de terminale ou de seconde par exemple, du fait des redoublements de la première partie du baccalauréat, ou encore des classes de septième trop peu peuplées, et de loin, à la veille de la guerre pour alimenter à elles seules les classes de sixième. La croissance des classes secondaires a obligé les établissements à stabiliser, voire à réduire les effectifs des petites classes. Une constatation qui dément l'opinion reçue et qui milite à la fois pour et contre l'école unique : pour, parce qu'elle prouve qu'il y a déjà avant la guerre un palier d'orientation à ce niveau et une large ouverture au recrutement dans les écoles primaires; contre parce que ces 
petites classes ont un effectif trop important pour qu'on puisse les supprimer sans déséquilibrer les établissements secondaires.

À côté de ces tendances générales, les profils pédagogiques dégagent des différences sensibles, notamment entre établissements masculins et féminins. Leur récente unification n'a pas encore porté tous ses effets à la veille de la guerre. Sans évoquer l'ambiance particulière des lycées et collèges de jeunes filles, qui s'est effacée très progressivement après qu'ils se soient ouverts aux garçons dans les années 1960-1970, et qui relève d'une analyse ethnographique, l'effectif de leurs sections et filières traduit deux usages sociaux contrastés. D'un côté, un usage moderne, qui conduit à des scolarités longues, souvent classiques, et traduisent la volonté de promotion par l'école de milieux plutôt modestes. De l'autre, des scolarités plus courtes, commencées dès les classes élémentaires, et qui s'achèvent avant le baccalauréat, relevant d'un modèle plus proche de celui du début du siècle. Encore courant autour de 1930, cet usage plus traditionnel n'a pas disparu la veille de la guerre.

Mais la croissance des effectifs du secondaire entre 1930 et 1938 s'est-elle accompagnée d'une démocratisation? Si l'on reprend les résultats de l'analyse factorielle des correspondances (graphique 10), le décalage entre les deux dates sur le premier axe, celui des groupes sociaux, le suggère. Cependant, l'évolution est faible. Nous ne pouvons raisonner ici en pourcentages d'enfants d'un milieu donné qui font des études secondaires, puisque nous n'avons pas de statistique nationale et encore moins locale sur l'effectif des divers groupes sociaux. Nous raisonnons donc en termes de mixité sociale, pesant le poids des différents milieux dans les lycées et collèges.

De ce point de vue, l'analyse montre d'abord la réalité d'une certaine mixité sociale : nous avons toujours trouvé dans les établissements des minorités d'enfants d'ouvriers, d'employés, de gens de métier, de petits fonctionnaires comme les gendarmes, plus rarement d'agriculteurs. Ils représentaient autour de 1930 $23,4 \%$ des effectifs des classes secondaires de garçons, et $15,1 \%$ de celles de filles, pourcentages qui s'établissent en 1938 à respectivement 24,4\% et 21,0\%. Si l'on tient compte en outre des commerçants et cadres moyens publics comme privés, un tiers de l'effectif de façon presque constante, ce n'est pas la bourgeoisie proprement dite qui domine le secondaire public - aucune comparaison n'étant possible avec le privé -; ce sont les classes moyennes et populaires.

À cette conclusion générale, il convient d'apporter aussitôt trois nuances : les établissements féminins sont plus bourgeois que ceux de garçons, les grands 
établissements plus que les petits; les classes moyennes se sont renforcées dans les années trente : elles sont les bénéficiaires de la croissance.

Ceci nous invite à revenir sur l'identification de la culture scolaire du secondaire à celle des classes dominantes. L'analyse fine des sections classiques confirme bien l'attachement des professions libérales au latin, et dans l'ensemble, celui des classes supérieures, avec des nuances, le monde de l'argent étant plus partagé. Mais les catégories intermédiaires, à l'exception des commerçants, tiennent tout autant à placer leurs enfants dans les sections classiques. Quand on fait partie des classes supérieures on peut se satisfaire d'humanités modernes, mais pour y accéder, rien ne vaut les humanités traditionnelles. L'enseignement secondaire classique et le latin sont avant tout la voie royale de l'ascension sociale.

Antoine Prost

Université de Paris 1-Panthéon-Sorbonne ap-prost@3dnet.fr 


\section{Annexes}

\section{Effectifs globaux des établissements secondaires 1921-1938}

\begin{tabular}{|c|c|c|c|c|c|}
\hline \multirow[t]{2}{*}{ Colonne 1} & \multirow{2}{*}{$\begin{array}{l}\text { Population } \\
\text { 11-15 ans* }\end{array}$} & \multirow{2}{*}{\begin{tabular}{|c|} 
Enseignement public \\
Garçons
\end{tabular}} & \multirow{2}{*}{$\begin{array}{c}\text { Colonne2 } \\
\text { Filles }\end{array}$} & \multirow{2}{*}{$\begin{array}{c}\text { Colonne3 } \\
\text { Total }\end{array}$} & \multirow[t]{2}{*}{ Enseigt. prive } \\
\hline & & & & & \\
\hline 1921 & 4165 & 113406 & 49007 & 162413 & 97188 \\
\hline 1922 & 4095 & 114910 & 49897 & 164807 & 100400 \\
\hline 1923 & 4068 & 117239 & 51235 & 168474 & 106563 \\
\hline 1924 & 4015 & & & & 109209 \\
\hline 1925 & 3949 & 120529 & 53960 & 174489 & 111573 \\
\hline 1926 & 3607 & 117308 & 51115 & 168423 & 115483 \\
\hline 1927 & 3201 & 115096 & 52459 & 167555 & 118909 \\
\hline 1928 & 2815 & 115683 & 53503 & 169186 & 120890 \\
\hline 1929 & 2495 & 119311 & 54788 & 174099 & 128861 \\
\hline 1930 & 2246 & 128299 & 59339 & 187638 & 147451 \\
\hline 1931 & 2599 & 141565 & 65718 & 207283 & 161492 \\
\hline 1932 & 3029 & 154730 & 72052 & 226782 & 181298 \\
\hline 1933 & 3379 & 160604 & 75897 & 236501 & 194003 \\
\hline 1934 & 3670 & 162391 & 77654 & 240045 & 211396 \\
\hline 1935 & 3919 & 166913 & 78740 & 245653 & 224451 \\
\hline 1936 & 3856 & 172579 & 81004 & 253583 & 226270 \\
\hline 1937 & 3811 & 181555 & 87867 & 269422 & 241566 \\
\hline 1938 & 3800 & 189048 & 93301 & 282349 & \\
\hline
\end{tabular}

Tableau I. Effectifs globaux des Établissements secondaires 1921-1938

* La population de 11 à 15 ans est la moyenne mobile des naissances en milliers calculée sur les cinq années qui précèdent l'année n de n-11 à n-15. La mortalité depuis la naissance n'a pas été prise en compte. Source : pour les effectifs de l'enseignement public, Annuaires statistiques annuels de la SGF pour l'Entredeux Guerres, et INSEE, Annuaire statistique de la France, résumé rétrospectif 1966, Paris, 1966, tableau XII, p. 139, et pour l'enseignement privé, ibid., tableau XVII, p. 141.

\section{Statistiques annuelles de la Statistique générale de la France}

Les tableaux ci-après sont la compilation de ceux de l'Annuaire statistique de la France publié chaque année par la Statistique générale de la France. Les totaux sont conformes à ceux qui figurent dans l'Annuaire statistique rétrospectif 1966 de l'INSEE 


\begin{tabular}{lc|c|c|c|c|c}
\hline & \multirow{5}{*}{$\begin{array}{c}\text { nombre } \\
\text { de lycées }\end{array}$} & \multicolumn{5}{|c}{ Effectif des élèves } \\
\cline { 3 - 6 } & & CPGE & Secondaires & Primaires & \multicolumn{1}{c}{ Spéciales } & \multicolumn{1}{c}{ Total } \\
\hline 1921 & & 3995 & 50621 & 19639 & 929 & 75184 \\
1922 & & 3919 & 51890 & 18773 & 881 & 75463 \\
1923 & 126 & 4002 & 53531 & 18257 & 899 & 76689 \\
1924 & 125 & 4019 & 55301 & 17625 & 996 & 77941 \\
1925 & 125 & 3914 & 56065 & 17776 & 1027 & 78782 \\
1926 & 126 & 3663 & 54156 & 18005 & 1067 & 76891 \\
1927 & 124 & 3791 & 51755 & 18780 & 1166 & 75492 \\
1928 & 124 & 4295 & 49435 & 20734 & 1574 & 76038 \\
1929 & 124 & 4894 & 48259 & 23469 & 1592 & 78214 \\
1930 & 123 & 5687 & 50324 & 26141 & 1610 & 83762 \\
1931 & 125 & 6391 & 55792 & 28463 & 1965 & 92611 \\
1932 & 125 & 6429 & 62156 & 28923 & 2246 & 99754 \\
1933 & 125 & 5799 & 65314 & 28460 & 2877 & 102450 \\
1934 & 125 & 4945 & 68167 & 27030 & 2974 & 103116 \\
1935 & 125 & 4764 & 72340 & 26489 & 3066 & 106659 \\
1936 & 126 & 4855 & 77403 & 25881 & 3235 & 111374 \\
1937 & 128 & 5586 & 84431 & 26197 & 3339 & 119553 \\
1938 & 130 & 7110 & 88325 & 25908 & 3424 & 124767 \\
\hline
\end{tabular}

Tableau II-a. Lycées de garçons

Note : à partir de 1932, l'effectif des classes secondaires publié par la SGF comprend celui des CPGE. Pour obtenir une série cohérente, nous l'avons déduit ici. Le total CPGE + Secondaire est conforme à celui publié par l'Annuaire rétrospectif 1939 de la SGF (p. 28*) sauf pour 1934 (103 208) et 1935 (106 567)

\begin{tabular}{|c|c|c|c|c|c|c|c|c|}
\hline & \multirow{2}{*}{$\begin{array}{l}\text { Nombre } \\
\text { de } \\
\text { collèges }\end{array}$} & \multicolumn{3}{|c|}{ Effectif des élèves } & \multicolumn{3}{|c|}{ Détail des "autres" } & \multirow{2}{*}{$\begin{array}{c}\text { Effecti } \\
\text { total }\end{array}$} \\
\hline & & Secondaires & Primaires & Autres & Profess. & EPS & EPCI & \\
\hline 1919 & & & & 4772 & 1300 & 2489 & 983 & \\
\hline 1920 & & & & 5254 & 1552 & 2872 & 830 & \\
\hline 1921 & & 20706 & 11888 & 5628 & 1450 & 3374 & 804 & 38222 \\
\hline 1922 & & 21463 & 11802 & 6182 & 1625 & 3603 & 954 & 39447 \\
\hline 1923 & 243 & 21898 & 11443 & 7209 & 2208 & 4058 & 943 & 40550 \\
\hline 1924 & 244 & 22865 & 11511 & 6814 & 1809 & 4083 & 922 & 41190 \\
\hline 1925 & 244 & 22741 & 11916 & 7090 & 1852 & 4547 & 691 & 41747 \\
\hline 1926 & 242 & 22023 & 11101 & 7293 & 1426 & 4612 & 1255 & 40417 \\
\hline 1927 & 237 & 20877 & 10759 & 7968 & 1261 & 5420 & 1287 & 39604 \\
\hline 1928 & 235 & 20038 & 11794 & 7813 & 1295 & 5612 & 906 & 39645 \\
\hline 1929 & 235 & 19648 & 13857 & 7592 & 1349 & 5331 & 912 & 41097 \\
\hline 1930 & 236 & 21124 & 15766 & 7647 & 870 & 5708 & 1069 & 44537 \\
\hline 1931 & 236 & 24045 & 17131 & 7778 & 1041 & 5730 & 1007 & 48954 \\
\hline 1932 & 229 & 27775 & 17179 & 10022 & & & & 54976 \\
\hline 1933 & 229 & 29827 & 16790 & 11537 & & & & 58154 \\
\hline 1934 & 225 & 31143 & 15775 & 12357 & & & & 59275 \\
\hline 1935 & 225 & 32843 & 14859 & 12552 & & & & 60254 \\
\hline 1936 & 224 & 34432 & 14481 & 12292 & & & & 61205 \\
\hline 1937 & 223 & 36297 & 14037 & 11668 & & & & 62002 \\
\hline 1938 & & 38505 & 13940 & 11836 & & & & 64281 \\
\hline
\end{tabular}

Tableau II-b. Collèges de garçons 


\begin{tabular}{l|c|c|c|c|c|c}
\hline & \multirow{2}{*}{$\begin{array}{c}\text { nombre } \\
\text { de lycées }\end{array}$} & \multicolumn{5}{|c}{ Effectif des élèves } \\
\cline { 3 - 6 } & & dont CPGE & Secondaires & Primaires & Spéciales & Total \\
\hline 1921 & 68 & & 17682 & 13282 & & 30964 \\
1922 & & 18258 & 12803 & & 31061 \\
1923 & 68 & & 18771 & 13014 & & 31785 \\
1924 & 68 & & & & & \\
1925 & 69 & & 22685 & 10860 & & 33545 \\
1926 & 70 & & 20160 & 11080 & & 31240 \\
1927 & 70 & & 21345 & 11468 & & 32813 \\
1928 & 72 & & 20623 & 12699 & 241 & 33563 \\
1929 & 72 & 479 & 20252 & 14124 & 331 & 34707 \\
1930 & 72 & 446 & 21197 & 15661 & 340 & 37198 \\
1931 & 73 & 421 & 23952 & 16649 & 449 & 41050 \\
1932 & 72 & 502 & 27454 & 16534 & 620 & 44608 \\
1933 & 72 & 558 & 29802 & 15876 & 653 & 46331 \\
1934 & 72 & 563 & 31761 & 15580 & 705 & 48046 \\
1935 & 73 & 476 & 33307 & 15154 & 755 & 49216 \\
1936 & 75 & 455 & 35757 & 14482 & 800 & 51039 \\
1937 & 77 & 613 & 41208 & 14448 & 890 & 56546 \\
1938 & 78 & 791 & 44987 & 14492 & 898 & 60377 \\
\hline
\end{tabular}

Tableau II-c. Lycées de filles

Note : les élèves des CPGE sont comptées dans l'effectif des classes secondaires

\begin{tabular}{l|c|c|c|c|c}
\hline & \multirow{2}{*}{$\begin{array}{c}\text { Nombre } \\
\text { de } \\
\text { collèges }\end{array}$} & \multicolumn{4}{|c}{ Effectif des élèves } \\
\cline { 3 - 5 } & Secondaires & Primaires & Spéciales & Total \\
\hline 1921 & 86 & 7440 & 6054 & & 13494 \\
1922 & 87 & 7944 & 6042 & & 13986 \\
1923 & 92 & 8440 & 6352 & & 14792 \\
1924 & 93 & & & & \\
1925 & 94 & 10254 & 5513 & & 15767 \\
1926 & 95 & 9926 & 5276 & & 15202 \\
1927 & 96 & 9645 & 5321 & & 14966 \\
1928 & 94 & 8567 & 5349 & 1276 & 15192 \\
1929 & 95 & 8064 & 5909 & 1477 & 15450 \\
1930 & 97 & 8737 & 6728 & 1981 & 17446 \\
1931 & 96 & 9635 & 7484 & 2032 & 19151 \\
1932 & 95 & 11387 & 7926 & 2816 & 22129 \\
1933 & 94 & 12559 & 8088 & 3358 & 24005 \\
1934 & 94 & 13058 & 7706 & 3317 & 24081 \\
1935 & 93 & 13499 & 7288 & 3356 & 24143 \\
1936 & 93 & 14240 & 7048 & 3447 & 24735 \\
1937 & 93 & 15428 & 7274 & 3624 & 26326 \\
1938 & 93 & 16584 & 7187 & 4195 & 27966 \\
\hline
\end{tabular}

Tableau II-d. Collèges de filles 


\begin{tabular}{lccccc}
\hline & \multirow{2}{*}{$\begin{array}{c}\text { Nombre } \\
\text { de cours }\end{array}$} & Secondaires & Primaires & Spéciales & Total \\
\hline 1921 & 48 & 2295 & 2254 & & 4549 \\
1922 & 45 & 2890 & 1960 & & 4850 \\
1923 & 43 & 2796 & 1862 & & 4658 \\
1924 & 41 & & & & 4634 \\
1925 & 43 & 3128 & 1520 & & 4648 \\
1926 & 40 & 3176 & 1497 & & 4673 \\
1927 & 39 & 3116 & 1564 & & 4680 \\
1928 & 39 & 2877 & 1701 & 170 & 4748 \\
1929 & 38 & 2856 & 1722 & 53 & 4631 \\
1930 & 36 & 2857 & 1774 & 64 & 4695 \\
1931 & 35 & 3206 & 1957 & 354 & 5517 \\
1932 & 30 & 3387 & 1795 & 133 & 5315 \\
1933 & 30 & 3616 & 1811 & 134 & 5561 \\
1934 & 30 & 3677 & 1709 & 141 & 5527 \\
1935 & 27 & 3622 & 1606 & 153 & 5381 \\
1936 & 27 & 3480 & 1574 & 176 & 5230 \\
1937 & 25 & 3180 & 1375 & 440 & 4995 \\
1938 & 24 & 3383 & 1274 & 301 & 4958 \\
\hline
\end{tabular}

Tableau II-e. Cours secondaires de filles

\section{Structure de la base de données}

\subsection{Construction de la base}

En toute rigueur, l'enquête aurait dû porter sur tous les départements, et sur les mêmes dates. Ce n'est pas le cas, et ce travail est à mi-chemin entre le bricolage et la science. L'idée en est née en 2004 à l'occasion du bicentenaire du lycée d'Argentan; son proviseur m'ayant demandé une conférence sur son histoire, j'avais regardé les archives qu'il conservait et le registre d'inscription que j'y ai trouvé a éveillé ma curiosité. Au fil des ans et de mes déplacements, j'ai donc cherché des registres analogues, et j'ai photographié ceux que j'ai trouvés, sans faire le difficile s'ils ne concernaient pas exactement 1930 ou 1938; j'ai sollicité de nombreux archivistes départementaux qui m'ont renseigné et souvent même fourni des fichiers numérisés, m'évitant le déplacement; des collègues bienveillants m'ont donné copie de registres conservés dans leur lycée. Que toutes et tous soient chaudement remerciés. Puis, comme je poursuivais d'autres recherches, je me suis lassé. Année après année, j'avais fait le tour de 55 départements et la base contenait plus de 15300 lycéens. Je n’ai pas voulu sacrifier d'autres travaux à poursuivre l'enquête dans les 33 départements métropolitains qui restaient (la Seine étant exclue) et plutôt que de l'abandonner, 
j'ai résolu d'exploiter cette enquête inachevée, d'autant que la base de données semble assez importante pour que les conclusions méritent considération.

L'enquête a donc porté sur 55 des 90 départements de l'époque. Parmi ces 55 départements :

- 28 ne conservaient pas de registres d'inscription ou, pour de rares exceptions, n'ont pas répondu à mes requêtes $(1,3,4,8,10,13,16,18,23,27,28,32$, $36,37,38,43,45,46,48,49,55,71,76,77,84,86,87,88)$;

- 6 conservaient des registres inexploitables (manque de certaines classes, professions non indiquées : 22, 25, 29, 31, 34, 54). C'est le cas des registres des lycées de Brest, Toulouse, Montpellier et Nancy;

- La collecte a porté sur 21 départements différents. Dans certains (02 p. ex.) elle concerne plusieurs établissements. En général, c'est le plus important, celui de la préfecture, mais pas toujours, car tout dépend de l'existence d'un registre exploitable : dans le Rhône, ceux du collège de Villefranche-sur-Saône et non du lycée Ampère, dans le Jura, celui du minuscule collège d'Arbois pour 1938 et pas celui du lycée de Lons-le-Saunier, etc.

Le plus souvent, les registres sont tenus sur des imprimés officiels, mais certains (Arbois, Saint-Lô) le sont sur des cahiers d'écoliers. Le ministère demandant les effectifs au 5 novembre et la rentrée s'effectuant le $1^{\text {er }}$ octobre, les secrétariats remplissaient le registre en octobre. Les élèves inscrits après le 5 novembre sont ajoutés à la liste. Seul le collège d'Argentan enregistre les élèves au fur et à mesure de leur inscription, en indiquant la classe et la date de leur entrée, et en regard, celles de leur sortie et son motif. Comme certains élèves sautent ou redoublent une classe, il nous a fallu un travail délicat pour reconstituer la composition approximative des classes en 1931.

Les registres, de format A3, comprennent des colonnes consacrées aux entrées (page de gauche et deux premières colonnes, généralement vides, de la page de droite), les autres colonnes de cette page enregistrant les sorties par date, quelle que soit la classe, ce qui les rend inexploitables. La figure 1 montre une page de gauche du registre du lycée de jeunes filles de Bordeaux pour l'année 1929-1930. 


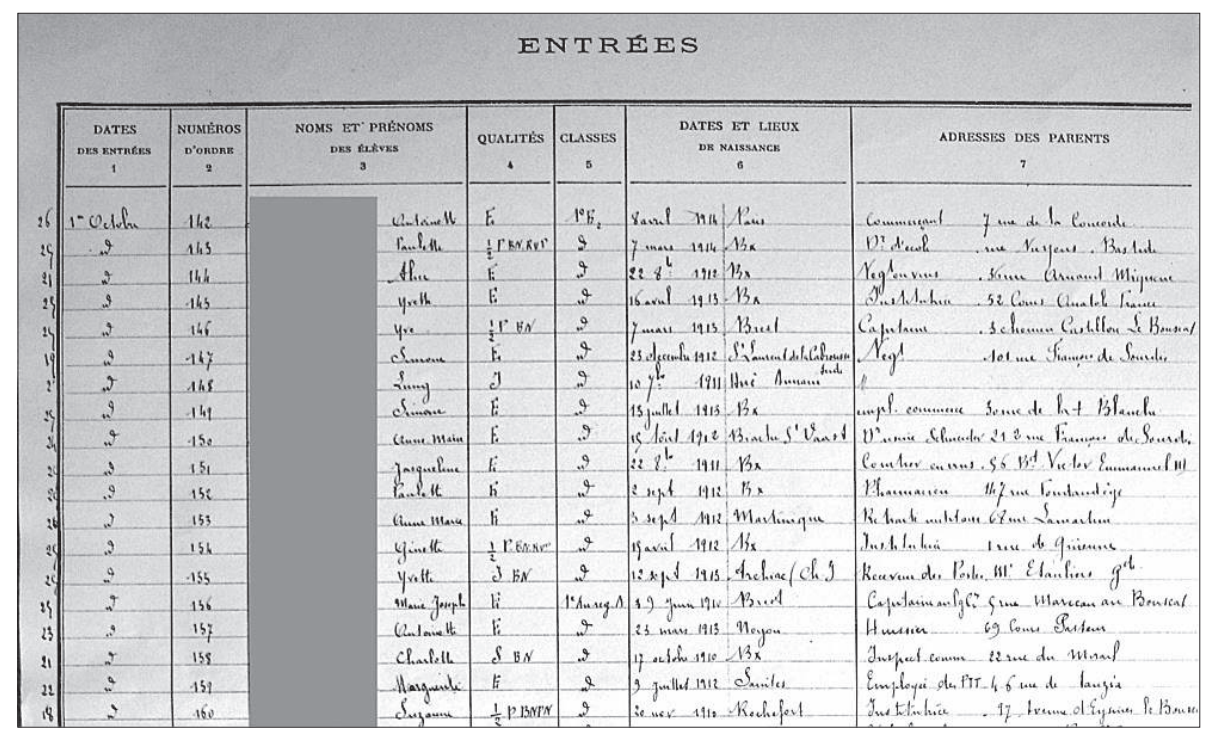

Figure 1 : page de du registre du lycée de jeunes filles de Bordeaux (année 1929-1930)

Certains registres comprennent des notations complémentaires, parfois la langue vivante, parfois les boursiers et pupilles de la Nation, les bénéficiaires de remises universitaires, comme ici dans la colonne "qualités", ailleurs dans une colonne libre.

J'ai dépouillé ces registres moi-même et saisi en clair toutes les informations à l'aide d'un tableur, constituant un fichier par établissement et année scolaire, quand la chance me donnait un registre exploitable pour le début et un autre pour la fin des années trente. J'ai respecté l'intitulé des sections, qui permet de repérer les latinistes, les dates exactes de naissance, et les libellés des professions tels qu'ils figuraient, remettant au codage la tâche d'interpréter les lexiques locaux. Ces fichiers regroupés constituent une base de données qui comprend 15384 élèves. On trouvera ci-après le détail de sa composition et un exemple de fichier d'établissement. 


\subsection{Composition de la base de données}

\begin{tabular}{|c|c|c|c|c|c|c|}
\hline \multirow{2}{*}{\multicolumn{2}{|c|}{ Etablissements }} & \multirow{2}{*}{ Années } & \multirow{2}{*}{ Cote } & \multicolumn{2}{|c|}{ Effectif } & \multirow{2}{*}{ Observations } \\
\hline & & & & 1930 & 1938 & \\
\hline A & L/G & 1929 & $1 T 6$ CIV 26 & 314 & & Avec boursiers \\
\hline Carcassonne & $L / G$ & 1938 & $1 T 355$ & & 756 & Avec cultes \\
\hline Clermont-Ferrand & $L / G$ & 1930 & A/lycie & 741 & & Avec boursiers et montant des bourses \\
\hline GAP & L/G & 1938 & T909 & & 644 & \\
\hline Laval & $L / G$ & 1937 & $3 \mathrm{~T} 110$ & & 293 & \\
\hline Rennes & $L / G$ & 1931 & $16 \mathrm{~T} 171$ & 699 & & \\
\hline \multirow[t]{2}{*}{ Rochefort } & $L / G$ & 1930 & $1 T 1068$ & 492 & & \\
\hline & & 1938 & $1 T 1069$ & & 597 & \\
\hline \multirow[t]{2}{*}{ Saint-Etienne } & L/G & 1930 & $\mathrm{~T} 2420$ & 778 & & \\
\hline & & 1937 & $T 2421$ & & 1134 & \\
\hline Sens & $L / G$ & 1938 & & & 343 & \\
\hline \multirow[t]{2}{*}{ Valence } & $L / G$ & 1930 & $634 W P 73-2 / 32$ & 325 & & \\
\hline & & 1938 & 634 WP73-2/33 & & 533 & \\
\hline Arbois & C/G & 1938 & Tp2257 & & 88 & \\
\hline Argentan & $C / G$ & $1931 \& 32$ & A/lycée & 179 & & Deux années \\
\hline Chäteau-Thierry & C/G & $1937 \& 38$ & A/lycée & & 491 & Deux années \\
\hline \multirow[t]{2}{*}{ Privas } & C/G & 1930 & "Collège Privas $16 "$ & 156 & & Avec cultes, LV, origine scolaire \\
\hline & C/G & 1938 & "Collège Privas 16" & & 284 & Avec origine scolaire \\
\hline Saint-Lổ & C/G & 1932 & & 277 & & \\
\hline \multirow[t]{2}{*}{ Soissons } & $C / G$ & 1930 & $1 \mathrm{~T} 1157$ & 252 & & \\
\hline & & 1938 & $1 \mathrm{T1158}$ & & 402 & \\
\hline Villefranche/Saônt & $C / G$ & 1942 & $1 T 2024$ & & 521 & \\
\hline Bordeaux & L/JF & 1930 & A/lycée & 900 & & Avec boursières \\
\hline \multirow[t]{2}{*}{ Dijon } & L/JF & 1930 & & 542 & & Avec boursières \\
\hline & & 1938 & & & 669 & \\
\hline Lille & L/JF & 1934 & $5 T 6$ & 915 & & \\
\hline \multirow[t]{2}{*}{ Blois } & $\mathrm{CS} / \mathrm{JF}$ & 1935 & $3 T 292$ & 229 & & \\
\hline & & 1939 & 3T292 & & 445 & \\
\hline \multirow[t]{2}{*}{ Montauban } & $C / J F$ & 1930 & & 301 & & \\
\hline & & 1938 & & & 385 & \\
\hline Saint-Quentin & $\mathrm{C} / \mathrm{JF}$ & 1937 & & & 699 & \\
\hline TOTAL & & & & 7100 & 8284 & \\
\hline
\end{tabular}

Figure 2 : composition de la base de données 


\subsection{Exemple de fichier d'établissement}

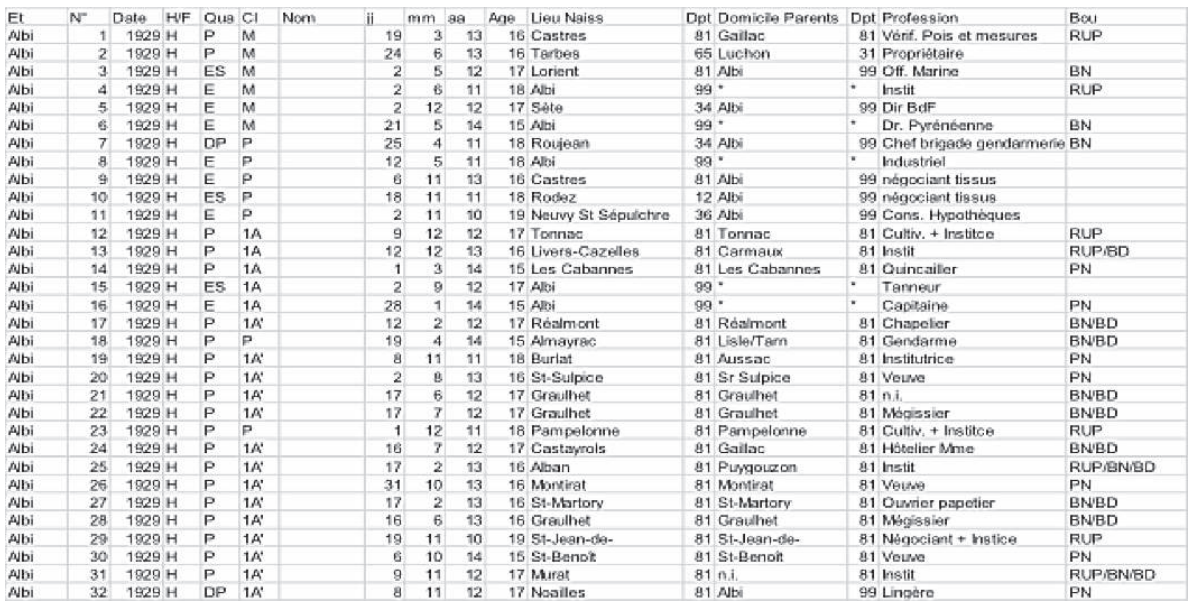

Figure 3 : exemple de fichier d'établissement

\subsection{Le codage des catégories sociales}

Le recrutement bourgeois de ces établissements nous a conduits à détailler la codification pour ce groupe. D'autre part, nous avons distingué entre secteur privé et secteur public, comme on l'a vu, pour la bourgeoisie, les cadres moyens et les employésa.

Notre codage comprend donc les catégories suivantes :

- 01 Bgs pri : la bourgeoisie privée, professions libérales, négociants et entrepreneurs, cadres supérieurs. Tous les entrepreneurs ont été classés dans ce groupe, bien que beaucoup parmi eux, par exemple dans les transports ou le bâtiment, ne fassent pas partie de la vraie bourgeoisie, mais il était impossible de les identifier. Les ingénieurs sont également un groupe hétérogène. Le titre d'ingénieur ayant été codifié et protégé en 1934 seulement, à côté d'ingénieurs

a. Ce codage repose sur des travaux précédents, notamment L'enseignement s'est-il démocratisé?, cité dans le texte de l'article. Voir également mon article : "Des registres aux structures sociales en France : réflexions sur la méthode", Le Mouvement social, n²46, janvier-mars 2014, p.97-117, et

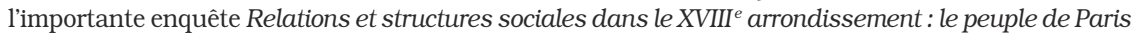
à l'époque du Front populaire, Rapport remis au PIR-Villes, mai 1996, multigr., 87 p. + annexes, dont j'ai présenté la méthode et les résultats dans "Les peuples du XVIII e arrondissement en 1936", in Jean-Louis Robert, Danielle Tartakowsky (dir.), Paris le peuple XVIII ${ }^{e} X X^{e}$ siècle, Paris, Publications de la Sorbonne, 1999, p.59-76 et "Les Parisiens de 1936 : la population du XVIII" arrondissement", in Claude Gauvart, Jean-Louis Robert, Etre Parisien, t. 55 de Paris et Ile-de-France, Mémoires publiés par la Fédération des sociétés historiques et archéologiques de Paris et de l'Ile-de-France, Paris, 2004, p. 23-46. 
diplômés de grandes écoles, d'autres, ingénieurs-mécaniciens ou électriciens par exemple, viennent d'une promotion interne et sont en fait nos actuels techniciens supérieurs. Nous nous sommes efforcés de distinguer les uns des autres et nous avons classé les premiers dans la bourgeoisie, les seconds parmi les cadres ou les fonctionnaires moyens;

- 02 Bgs pu : la bourgeoisie du secteur public : magistrats, officiers, cadres supérieurs des administrations, professeurs du secondaire et du supérieur;

- 03 CMoy pri : la classe moyenne du secteur privé : chefs de bureau ou de service, contremaîtres et chefs d'atelier ou de chantier, compétences diverses;

- 04 CMoy pu. : la classe moyenne du secteur public : sous-officiers, instituteurs, chefs de bureau, percepteurs, inspecteurs des impôts;

- 05 Comm : les commerçants, les négociants étant classés dans la bourgeoisie;

- $06 \mathrm{Empl}$ pri : les employés de commerce ou de banque, et les employés sans autre indication, notamment les comptables qui n'ont généralement pas de qualification à cette époque, la comptabilité se bornant à additionner des dépenses et des recettes sur deux colonnes. Les experts comptables sont classés dans la bourgeoisie. Les employés de chemins de fer sont dans ce groupe, les ouvriers étant généralement désignés plus précisément (mécanicien par ex.);

- $07 \mathrm{Empl} \mathrm{pu} \mathrm{:} \mathrm{les} \mathrm{petits} \mathrm{fonctionnaires,} \mathrm{facteurs,} \mathrm{cantonniers,} \mathrm{etc.;}$

- 08 Métiers : le monde des métiers. Nous regroupons ici les travailleurs manuels auxquels leur qualification permet de s'installer à leur compte, mais qui peuvent également s'employer chez un patron. Les mécaniciens, les électriciens, les serruriers, les menuisiers, mais aussi les tailleurs ou les maroquiniers.

- 09 Ouvriers : les ouvriers sans qualification autorisant l'accès au statut indépendant : manœuvres, hommes de peine, gardes, palefreniers, etc.;

- 10 Agri : les agriculteurs, avec la difficulté de les séparer des propriétaires. Dans le midi notamment, nombre de vignerons se déclarent propriétaires sans qu'on puisse évaluer l'importance de leur propriété;

- 11 Inactifs : les inactifs, à l'exception des rentiers et propriétaires sans autre indication, classés avec la bourgeoisie privée. Cette catégorie comprend les femmes seules;

- 12 n.i. : sans indication de profession.

On peut contester cette taxinomie. La connaissance de la société de l'entredeux-guerres, même étayée par d'autres enquêtes sociologiques, ne suffit pas à la justifier, ni plus ni moins que toute autre grille d'analyse. Sa principale justification est heuristique : c'est à ses résultats qu'on la jugera. 


\section{Tableaux de résultats}

Pour ne pas multiplier les tableaux, nous ne donnons ici que des tableaux de pourcentages, les effectifs totaux étant toujours mentionnés.

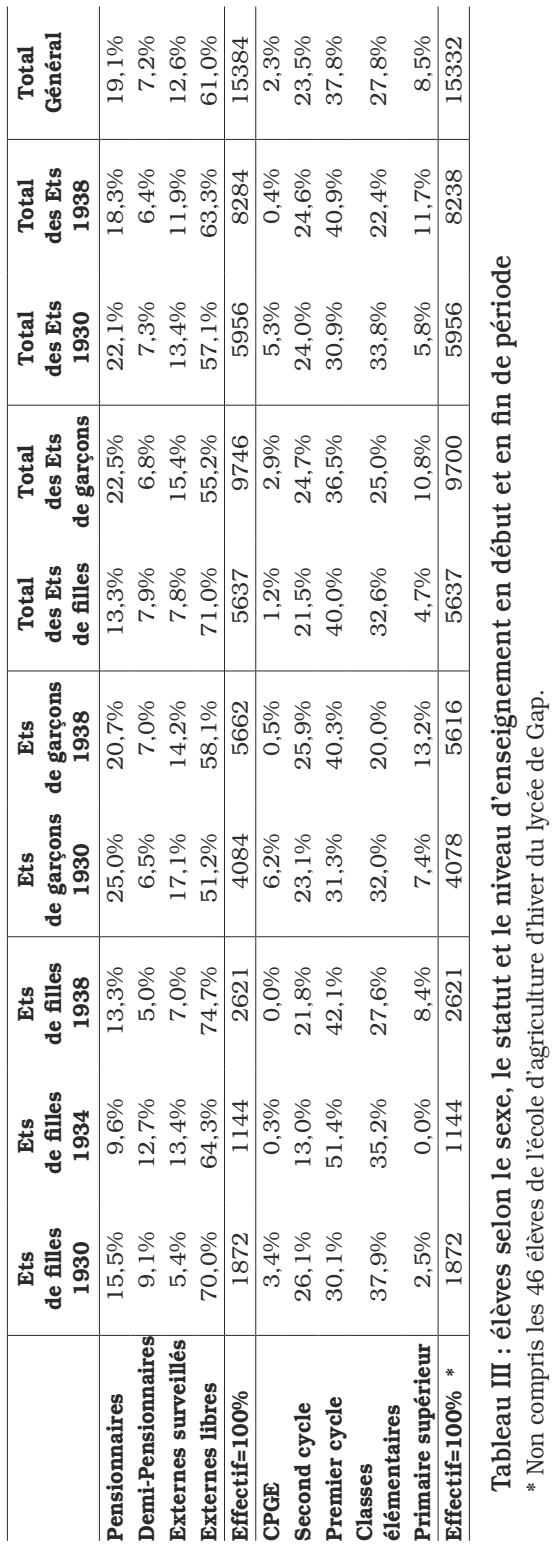

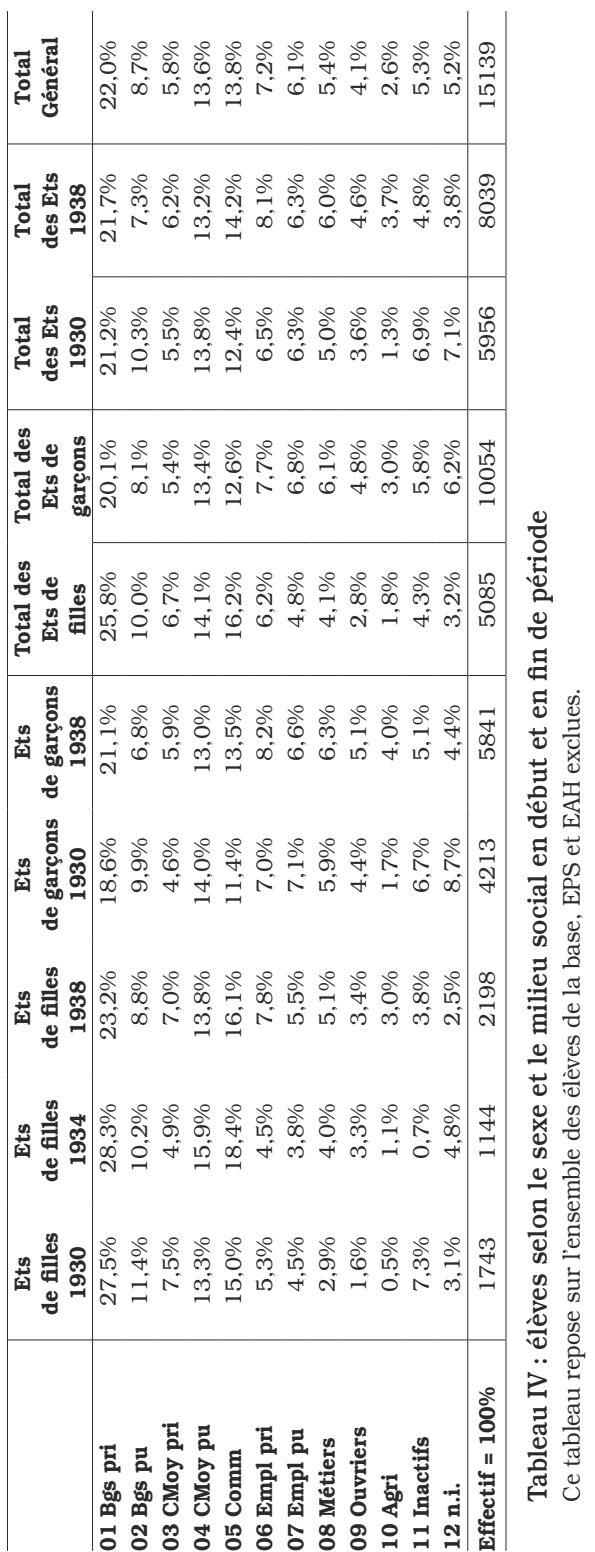




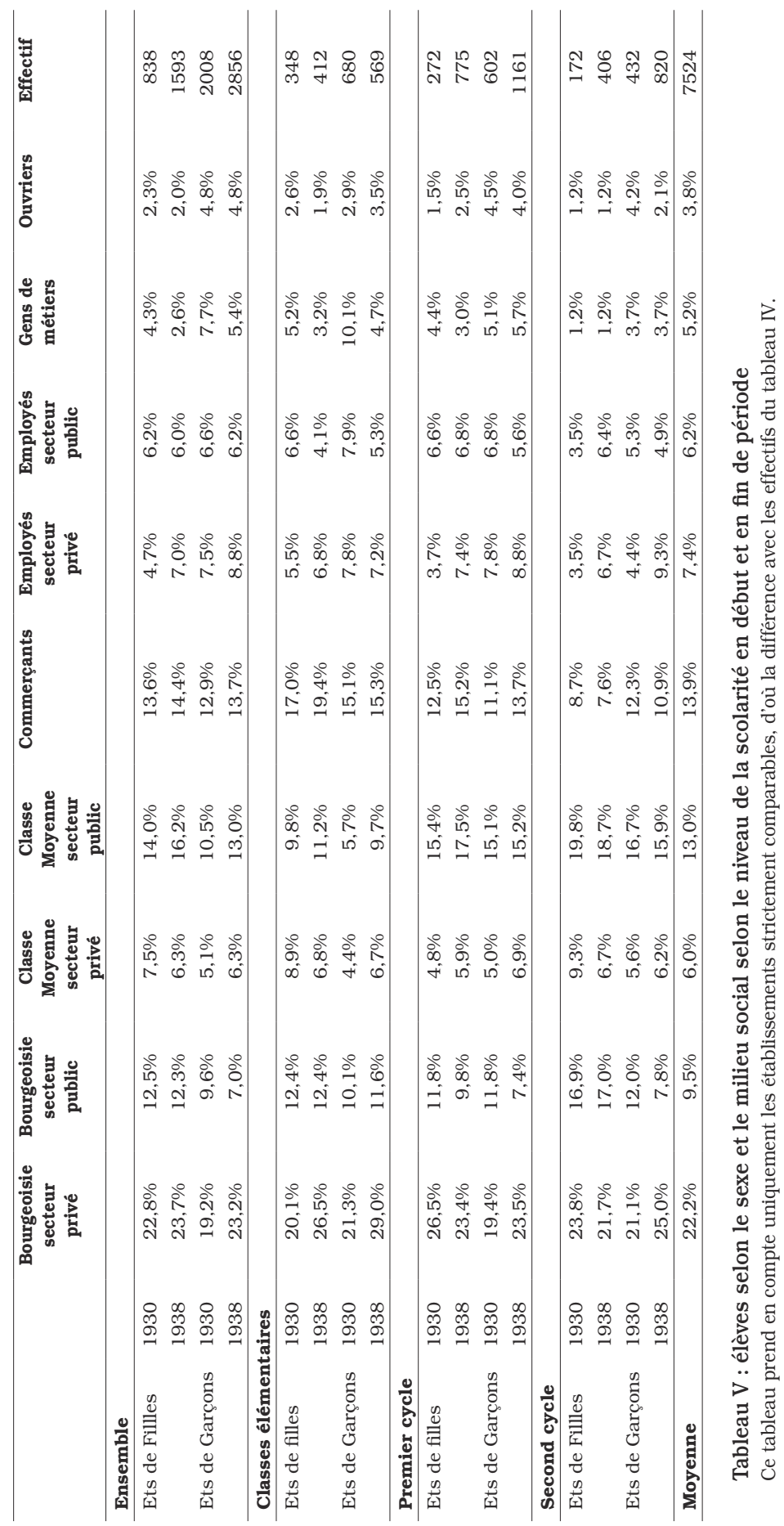




\begin{tabular}{l|c|c|c|c|c}
\hline & Classique & Moderne & Autre & n.i. & Moyenne \\
\hline 01 Bgs pri & $23,3 \%$ & $23,5 \%$ & $6,6 \%$ & $21,4 \%$ & $21,1 \%$ \\
02 Bgs pu & $18,8 \%$ & $11,9 \%$ & $6,9 \%$ & $16,3 \%$ & $14,9 \%$ \\
06 Empl & $12,0 \%$ & $16,3 \%$ & $12,5 \%$ & $11,2 \%$ & $13,4 \%$ \\
04 CMoy pu & $9,4 \%$ & $7,3 \%$ & $0,8 \%$ & $14,3 \%$ & $7,6 \%$ \\
03 CMoy pri & $6,9 \%$ & $7,3 \%$ & $13,4 \%$ & $4,1 \%$ & $7,9 \%$ \\
05 Comm & $6,3 \%$ & $5,8 \%$ & $5,0 \%$ & $2,0 \%$ & $5,9 \%$ \\
07 Empl pu & $6,1 \%$ & $5,3 \%$ & $9,9 \%$ & $3,1 \%$ & $6,3 \%$ \\
09 Ouvr & $5,3 \%$ & $5,1 \%$ & $6,8 \%$ & $7,1 \%$ & $5,5 \%$ \\
11 Inact & $3,9 \%$ & $5,2 \%$ & $10,9 \%$ & $5,1 \%$ & $5,3 \%$ \\
10 Agr & $3,4 \%$ & $4,7 \%$ & $7,2 \%$ & $11,2 \%$ & $4,4 \%$ \\
08 Mét & $2,7 \%$ & $4,3 \%$ & $13,7 \%$ & $2,0 \%$ & $4,7 \%$ \\
12 n.i. & $1,9 \%$ & $3,2 \%$ & $6,0 \%$ & $2,0 \%$ & $2,9 \%$ \\
\hline Effectif=100\% & 5130 & 3075 & 1310 & 100 & 9615 \\
\hline
\end{tabular}

Tableau VI : importance relative des divers groupes sociaux par filières de la sixième à la première

\begin{tabular}{l|r|r|r|r|r}
\hline & Classique & Moderne & Autre & n.i. & Effectif=100\% \\
\hline 01 Bgs pri & $59,0 \%$ & $35,7 \%$ & $4,3 \%$ & $1,0 \%$ & 2024 \\
02 Bgs pu & $65,7 \%$ & $30,9 \%$ & $1,5 \%$ & $1,9 \%$ & 732 \\
03 CMoy pri & $56,5 \%$ & $31,5 \%$ & $11,6 \%$ & $0,4 \%$ & 568 \\
04 CMoy pu & $67,0 \%$ & $25,5 \%$ & $6,3 \%$ & $1,2 \%$ & 1438 \\
05 Comm & $47,6 \%$ & $38,8 \%$ & $12,7 \%$ & $0,9 \%$ & 1291 \\
06 Empl & $46,8 \%$ & $29,6 \%$ & $23,1 \%$ & $0,5 \%$ & 761 \\
07 Empl pu & $51,6 \%$ & $26,5 \%$ & $21,3 \%$ & $0,7 \%$ & 611 \\
08 Mét & $39,5 \%$ & $31,4 \%$ & $28,1 \%$ & $1,0 \%$ & 509 \\
09 Ouvr & $30,7 \%$ & $29,1 \%$ & $39,7 \%$ & $0,4 \%$ & 453 \\
10 Agr & $35,8 \%$ & $35,1 \%$ & $28,3 \%$ & $0,7 \%$ & 279 \\
11 Inact & $51,7 \%$ & $30,0 \%$ & $16,9 \%$ & $1,3 \%$ & 526 \\
12 n.i. & $40,7 \%$ & $34,5 \%$ & $22,2 \%$ & $2,6 \%$ & 423 \\
\hline Moyenne & $53,4 \%$ & $32,0 \%$ & $13,6 \%$ & $1,0 \%$ & 9615 \\
\hline
\end{tabular}

Tableau VII : Importance relative des différentes filières selon les groupes sociaux 


\begin{tabular}{l|c|c|c|c|c}
\hline & Classique & Moderne & Autre & n.i. & Effectif=100\% \\
\hline Instituteur & $70,1 \%$ & $24,1 \%$ & $4,8 \%$ & $1,0 \%$ & 769 \\
Petit fonctionnaire & $51,6 \%$ & $26,5 \%$ & $21,3 \%$ & $0,7 \%$ & 611 \\
Fonct. Moyen & $67,3 \%$ & $26,4 \%$ & $4,8 \%$ & $1,5 \%$ & 602 \\
Bourgeoisie d'affaires & $54,1 \%$ & $41,9 \%$ & $2,4 \%$ & $1,6 \%$ & 549 \\
Cadre supérieur & $60,9 \%$ & $35,0 \%$ & $2,8 \%$ & $1,3 \%$ & 532 \\
Profession libérale & $73,3 \%$ & $24,1 \%$ & $1,8 \%$ & $0,8 \%$ & 514 \\
Gens de métiers & $39,5 \%$ & $31,4 \%$ & $28,1 \%$ & $1,0 \%$ & 509 \\
Commerçant & $44,3 \%$ & $43,0 \%$ & $11,9 \%$ & $0,8 \%$ & 488 \\
Ouvriers & $30,7 \%$ & $29,1 \%$ & $39,7 \%$ & $0,4 \%$ & 453 \\
Officier & $61,1 \%$ & $35,7 \%$ & $2,1 \%$ & $1,2 \%$ & 339 \\
Cadre moyen & $60,2 \%$ & $31,3 \%$ & $8,5 \%$ & $0,0 \%$ & 294 \\
Empl. Ch. Fer & $38,5 \%$ & $28,5 \%$ & $31,9 \%$ & $1,1 \%$ & 270 \\
Propriétaire & $49,3 \%$ & $41,9 \%$ & $8,7 \%$ & $0,0 \%$ & 229 \\
Entrepreneur & $41,5 \%$ & $43,0 \%$ & $15,0 \%$ & $0,5 \%$ & 200 \\
Professeur & $72,4 \%$ & $24,9 \%$ & $0,0 \%$ & $2,8 \%$ & 181
\end{tabular}

Tableau VIII : importance relative des différentes filières pour quelques professions

* Moyenne sur l'ensemble des élèves de la sixième à la première et non sur ceux des professions considérées 


\begin{tabular}{|c|c|c|c|c|c|c|c|c|c|}
\hline Etablissements & Boursiers & $\begin{array}{l}\text { Effectif } \\
\text { total }\end{array}$ & $\begin{array}{l}\text { \% de } \\
\text { boursiers }\end{array}$ & 1er Cycle & 2d Cycle & Classique & Moderne & CPGE & $\begin{array}{l}\text { Primaire } \\
\text { Supérieur }\end{array}$ \\
\hline $\begin{array}{l}\text { LG Clermont- } \\
\text { Ferrand } 1930\end{array}$ & 178 & 741 & $24,0 \%$ & $20,0 \%$ & $27,7 \%$ & $24,7 \%$ & $16,7 \%$ & \multirow[t]{3}{*}{$77,3 \%$} & \multirow{5}{*}{$36,7 \%$} \\
\hline $\begin{array}{l}\text { CG Soissons } \\
1930\end{array}$ & 60 & 252 & $23,8 \%$ & $39,3 \%$ & $31,4 \%$ & $36,1 \%$ & $35,7 \%$ & & \\
\hline $\begin{array}{l}\text { CF Montauban } \\
1930\end{array}$ & 61 & 301 & $20,3 \%$ & $31,3 \%$ & $36,1 \% *$ & & $31,7 \%$ & & \\
\hline $\begin{array}{l}\text { LF Bordeaux } \\
1929\end{array}$ & 160 & 900 & $17,8 \%$ & $21,1 \%$ & $23,3 \%$ & $28,2 \%$ & $14,6 \%$ & \multirow[t]{2}{*}{$81,6 \%$} & \\
\hline LG Albi 1929 & 50 & 314 & $15,9 \%$ & $27,9 \%$ & $24,1 \%$ & $30,5 \%$ & $10,3 \%$ & & \\
\hline LF Lille 1934 & 100 & 915 & $10,9 \%$ & $10,9 \%$ & $32,3 \%$ & $13,1 \%$ & $13,6 \%$ & & \\
\hline CS Blois 1935 & 8 & 229 & $3,5 \%$ & $5,4 \%$ & $15,8 \%$ & $9,2 \%$ & $4,3 \%$ & & \\
\hline $\begin{array}{l}\text { CG Château- } \\
\text { Thierry 1937-38 }\end{array}$ & 67 & 491 & $13,6 \%$ & $2,5 \%$ & $39,8 \%$ & $15,3 \%$ & $17,5 \%$ & \multirow{6}{*}{$10,0 \%$} & \multirow[t]{6}{*}{$18,1 \%$} \\
\hline $\begin{array}{l}\text { LG Carcassonne } \\
1938\end{array}$ & 74 & 756 & $9,8 \%$ & $6,6 \%$ & $18,6 \%$ & $10,4 \%$ & $3,2 \%$ & & \\
\hline LG Gap 1938 & 54 & 598 & $9,0 \%$ & $4,9 \%$ & $14,9 \%$ & $8,0 \%$ & $13,8 \%$ & & \\
\hline $\begin{array}{l}\text { LG St.-Etienne } \\
1937\end{array}$ & 69 & 1134 & $6,1 \%$ & $4,9 \%$ & $11,3 \%$ & $7,6 \%$ & $5,1 \%$ & & \\
\hline CS Blois 1939 & 20 & 445 & $4,5 \%$ & $4,7 \%$ & $11,4 \%$ & $8,0 \%$ & $3,6 \%$ & & \\
\hline LF Dijon 1938 & 22 & 669 & $3,3 \%$ & $2,8 \%$ & $7,8 \%$ & $4,6 \%$ & $1,2 \%$ & & \\
\hline Total général & 923 & 7745 & $11,9 \%$ & $10,4 \%$ & $20,5 \%$ & $13,6 \%$ & $13,5 \%$ & $66,9 \%$ & $20,6 \%$ \\
\hline Début de période & 509 & 2508 & $20,3 \%$ & $24,4 \%$ & $26,6 \%$ & $22,1 \%$ & $19,0 \%$ & $78,5 \%$ & $36,7 \%$ \\
\hline Fin de période & 306 & 4093 & $7,5 \%$ & $4,7 \%$ & $15,1 \%$ & $8,4 \%$ & $8,8 \%$ & $10,0 \%$ & $17,6 \%$ \\
\hline
\end{tabular}

Tableau IX : proportion de boursiers par établissement et par niveau de scolarité

Ce tableau ne concerne que les établissements dont les registres précisent si les élèves sont boursiers et il prend en compte tous les boursiers, quel que soit l'instance qui finance la bourse (très majoritairement l'État, mais aussi le département, et dans quelques cas, l'établissement lui-même ou une autorité étrangère). 